\title{
QUEEN'S
QNEIVERSITY
BELFAST
}

\section{Development of essentialist thinking about religion categories in Northern Ireland (and the United States)}

Smyth, K., Feeney, A., Eidson, R. C., \& Coley, J. D. (2017). Development of essentialist thinking about religion categories in Northern Ireland (and the United States). Developmental Psychology, 53(3), 475-496.

https://doi.org/10.1037/dev0000253

\section{Published in:}

Developmental Psychology

Document Version:

Publisher's PDF, also known as Version of record

Queen's University Belfast - Research Portal:

Link to publication record in Queen's University Belfast Research Portal

Publisher rights

(C) 2017 American Psychological Association.

This work is made available online in accordance with the publisher's policies. Please refer to any applicable terms of use of the publisher.

\section{General rights}

Copyright for the publications made accessible via the Queen's University Belfast Research Portal is retained by the author(s) and / or other copyright owners and it is a condition of accessing these publications that users recognise and abide by the legal requirements associated with these rights.

Take down policy

The Research Portal is Queen's institutional repository that provides access to Queen's research output. Every effort has been made to ensure that content in the Research Portal does not infringe any person's rights, or applicable UK laws. If you discover content in the Research Portal that you believe breaches copyright or violates any law, please contact openaccess@qub.ac.uk. 
Development of essentialist thinking about religion categories in Northern Ireland (and the United States)

\author{
Kirsty Smyth ${ }^{1}$, Aidan Feeney ${ }^{1}$, R. Cole Eidson ${ }^{2} \&$ John D Coley ${ }^{2}$ \\ ${ }^{1}$ Queen’s University Belfast \\ ${ }^{2}$ Northeastern University
}

Word count (excluding front page, title and references): 14337

Running head: Essentialist thinking about religion categories

Copyright APA. This article may not exactly replicate the final version published in the APA journal. It is not the copy of record which, when published, will be found at http://www.apa.org/pubs/journals/dev/index.aspx

\title{
Author Note
}

Kirsty Smyth and Aidan Feeney, School of Psychology, Queen’s University Belfast; R. Cole Eidson and John D. Coley, Department of Psychology, Northeastern University.

We are grateful to the children and schools who helped us with this work. Kirsty Smyth was supported by a PhD studentship from the Department of Employment and Learning, Northern Ireland.

Correspondence about this article should be addressed to Aidan Feeney, School of Psychology, Queen’s University Belfast, University Road, Belfast BT7 1NN, Northern Ireland. E-mail: a.feeney@qub.ac.uk. 


\begin{abstract}
Social essentialism, the belief that members of certain social categories share unobservable properties, licenses expectations that those categories are natural and a good basis for inference. A challenge for cognitive developmental theory is to give an account of how children come to develop essentialist beliefs about socially important categories. Previous evidence from Israel suggests that kindergarteners selectively engage in essentialist reasoning about culturally salient (ethnicity) categories, and that this is attenuated among children in integrated schools. In five studies (N=718) we used forced-choice (Study 1) and unconstrained (Studies 2-4) categorybased inference tasks, and a questionnaire (Study 5) to study the development of essentialist reasoning about religion categories in Northern Ireland (Studies 1-3 \& 5) and the US (Study 4). Results show that, as in Israel, Northern Irish children selectively engage in essentialist reasoning about culturally salient (religion) categories, and that such reasoning is attenuated among children in integrated schools. However, the development trajectory of essentialist thinking and the patterns of attenuation among children attending integrated schools in Northern Ireland differ from the Israeli case. Meta-analysis confirmed this claim and ruled out an alternative explanation of the results based on community diversity. Although the Northern Irish and Israeli case studies illustrate that children develop selective essentialist beliefs about socially important categories, and that these beliefs are impacted by educational context, the differences between them emphasize the importance of historical, cultural, and political context in understanding conceptual development, and suggest that there may be more than one developmental route to social essentialism.
\end{abstract}


Key words: social essentialism; category-based inference; integrated education; cross-cultural comparison; reasoning 


\section{Development of essentialist thinking about religion categories in Northern Ireland}

\section{(and the United States)}

Psychological essentialism is the belief that natural categories contain an underlying essence that conveys category membership and causes category members to share both observable and hidden properties (Gelman, 2003; Medin \& Ortony, 1989). In some cases, essentialist thinking can be useful. For example, using “essentialized” categories for inference provides us with an important tool to reduce the complexity of incoming information to manageable levels, and allows us to organize what we know and make inferences about what we don't know. However, essentialist thinking can also be harmful and lead to overgeneralization or unwarranted assumptions of homogeneity, especially when essentialist thinking is applied to social categories (e.g. Bastian \& Haslam, 2006; Diesendruck, 2013; Leslie, Cimpian, Meyer \& Freeland, 2015). In this paper we examine the development of essentialist thinking about socially important religion categoriesCatholic and Protestant - in Northern Ireland, with particular attention toward how school and national context may contribute to differences in the use of social categories to guide inferences.

Essentialist thinking about social categories in particular has been widely investigated (e.g., Haslam, Rothschild \& Ernst, 2000; Hirschfeld, 1996; Rhodes \& Gelman, 2009; Rothbart \& Taylor, 1992; Yzerbyt, Corneille \& Estrada, 2001), and there have been a variety of suggestions about its causes. One possibility is that it may represent an application of the same fundamental conceptual machinery that we use for thinking about natural kinds to the critical task of navigating our complex social environment (Gil-White, 2001). Another view is that a general purpose set of biases or heuristics results in the development of essentialist thinking about a variety of domains (Cimpian \& Salomon, 2014; Gelman, 2003). Regardless of how it is 
explained, essentialist thinking about the social world can also lead us to weigh social category membership over individual qualities, making it one of several candidate causes (e.g. Sherif, Harvey, White, Hood \& Sherif, 1961; Tajfel, 1982) of stereotyping, prejudice, and discrimination (Bastian \& Haslam, 2006; Diesendruck, 2013; Haslam, Bastian, Bain \& Kashima, 2006; Pauker, Ambady \& Apfelbaum, 2010; Prentice \& Miller, 2007). As a cognitive mechanism that may provide a foundation for stereotypical and prejudicial thinking, it is important to understand how social essentialism develops in different contexts.

Although there is now quite a large literature on how the tendency to essentialise social categories develops, drawing firm conclusions from that literature is not straightforward. One difficulty lies in the range of categories and national contexts that have been studied. For example, ethno-religious categories are essentialized in Israel (see Diesendruck, Goldfein-Elbaz, Rhodes, Gelman \& Neumark, 2013; Diesendruck \& HaLevi, 2006; Segall, Birnbaum, Deeb \& Diesendruck, 2015), social class categories are essentialized in India (Mahalingham, 2003) and race categories are essentialized in the US (Hirschfeld, 1996). Furthermore, a wide range of tasks has been used to study essentialism. Some researchers take children’s willingness to base inferences about novel behaviour on membership in social categories as evidence of essentialism (see Birnbaum, Deeb, Segall, Ben-Eliyahu \& Diesendruck, 2010; Diesendruck \& HaLevi, 2006), others have examined children’s beliefs about category stability over time (see Kinzler \& Dautel, 2012), and yet others study children's beliefs about the degree to which categories are arbitrary and artificial versus objective and natural (see Diesndruck, Goldfein-Elbaz, et al., 2013; Rhodes \& Gelman, 2009). 
Perhaps this wide variety of categories, and tasks used to study them, explains why there is evidence for early (Birnbaum et al., 2010; Byers-Heinlein \& Garcia, 2014; Diesendruck, Goldfein-Elbaz, et al., 2013; Kinsler \& Dautel, 2012) and late (Rhodes \& Gelman, 2009) emerging differences in levels of essentialist beliefs between different cultural and national groups, as well as why those differences have been shown to come about via increases (see Birnbaum et al., 2010), decreases (Deeb, Segall, Birnbaum, Ben-Eliyahu \& Diesendruck, 2011) or increases and decreases (Rhodes \& Gelman, 2009) in essentialist thinking about social categories amongst children exposed to particular contexts. Taken together, these studies present a suggestive but incomplete picture. Whereas the tendency to essentialise social categories appears to have been detected in every population studied, different social categories are essentialised at different times by different groups of children. Thus, it is hard to tell whether it is the nature of the categories or the nature of the context which is important. In order to draw general conclusions about how and why children display essentialist reasoning about social categories, detailed study of particular categories in particular national contexts is required.

\section{Ethnicity categories in Israel}

By far the most comprehensive case study in the literature has been provided by Diesendruck and his colleagues in their study of Israeli children's essentialist beliefs about ethnic categories (Birnbaum et al., 2010; Deeb et al., 2011; Diesendruck, Birnbaum, Deeb \& Segall, 2013;

Diesendruck, Goldfein-Elbaz, et al., 2013; Diesendruck \& HaLevei, 2006; Segall et al., 2015). In a series of important papers, it has been shown using a variety of experimental tasks and questionnaires, that Israeli children essentialise ethnicity categories from a young age. Diesendruck \& HaLevi (2006) showed that secular Jewish kindergarteners preferred to make 
social inferences based on membership of ethnicity (Arab, Jew) and social class categories rather than based on shared personality characteristics. In a somewhat different task, Birnbaum et al. (2010) examined Israeli children’s willingness to base inferences about novel behaviour on competing cues related to membership in ethnicity categories, gender, religiosity, and social status. Religious Jewish children preferentially used ethnicity to guide inferences, and showed little change in this tendency between kindergarten and $6^{\text {th }}$ grade. In contrast, secular Jewish children and Arab children showed no preference for any category. More recent work (Segall et al., 2015) suggests that parental use of generic terms (e.g. Jews, Arabs) to refer to social categories, is the strongest predictor of Israeli kindergarten children's beliefs about the naturalness of ethnicity categories.

Diesendruck and colleagues have also studied the effect of educational environment on essentialist beliefs about social categories in Israel. The context in which children grow up could be important for shaping essentialist thinking about social categories (e.g., Rhodes, 2013), and one contextual factor that is likely to have a large impact is the diversity of one's immediate social environment. The effects of contact with members of diverse social groups on social cognition are well known (e.g., Allport, 1954; Crisp \& Turner, 2011; Pettigrew, 1998), and indeed, Deeb et al. (2011) present evidence that children in diverse social environments may display lower levels of essentialist thinking as well. Specifically, Deeb et al. (2011) report that, based on the Essentialism Components Questionnaire (Diesendruck \& Haber, 2009), Israeli Jewish and Arab children attending integrated schools were less likely to exhibit essentialist thinking about inheritance and psychological characteristics than children attending traditional schools. Older children in this study reported lower levels of essentialist beliefs than younger 
children, but this drop in essentialist beliefs occurred earlier for Jewish children attending integrated schools. Thus, in Israel, a diverse educational environment appears to attenuate the relatively high levels of essentialist beliefs about ethnicity categories with which children appear to arrive at school.

Further evidence that Israeli children may have strong essentialist beliefs about ethnicity, and other social categories, comes from a study (Diesendruck, Goldfein-Elbaz, et al., 2013) that examined the degree to which children in Israel and the US viewed race (Black, White) and ethnicity (Arab, Jewish) categories (along with gender, occupation, animal, and artefact categories) as arbitrary and artificial versus objective and natural. Results suggested that ethnicity was more highly essentialized for Israeli children than for US children; Israeli children were less willing to accept alternative categorization for ethnicity than any other kind of category, whereas ethnicity was less salient for US children. However, race was no more highly essentialized among US children than among Israeli children. And although they do not discuss it directly, the data reported by Diesendruck et al. hint at overall national differences in beliefs about the naturalness of social categories; the mean probability of rejecting an alternative category was $66 \%$ for Israeli children and only $52 \%$ for US children, suggesting that Israeli children may be more prone to essentialist thinking in general about social categories than US children.

Thus, the picture from Israel is one of (a) high levels of essentialist thinking about social categories in general and ethnicity categories specifically, (b) early emerging essentialism of ethnicity categories perhaps related to parental input, and (c) a general decrease in essentialist thinking with age, which occurs earlier amongst Jewish children attending integrated schools. 
However, it’s not clear the degree to which these findings about ethnicity categories in Israel represent general developmental patterns or are specific to a given political, historical, and cultural context. As such, it is important to carry out other case studies, on other social categories in other national contexts. To this end, we present an exploration of the development of essentialist thinking about religion categories (Catholic, Protestant) in Northern Ireland as another case study to complement the Israel one. Additionally, although effects of educational context on responses to questionnaires has been studied in Israel (see Deeb et al., 2011), to our knowledge there has been no study of the effects of educational diversity on experimental tasks typically used to measure essentialist thinking about social categories. Accordingly, we were particularly interested in the effects of educational diversity in Northern Ireland.

\section{The current study: Religion categories in Northern Ireland}

Northern Ireland has long been the locus of ethno-political-religious conflict between Nationalists who favour unity with the Republic of Ireland (and tend to be Catholic and ethnically Irish) and Unionists who favour Northern Ireland remaining a part of the United Kingdom (and tend to be Protestant and ethnically English or Scottish). Although dating back centuries, this conflict was most recently manifest in “The Troubles,” a period from 1968 to 1998 when thousands were killed and injured. As a result, religious affiliation-i.e., membership in the category Catholic or Protestant—remains a critically important social dimension in Northern Ireland today (see Gillespie, 2010) and Northern Irish society is subject to high levels of residential (see Shuttleworth \& Lloyd, 2009), marital (Lloyd \& Robinson, 2011) and educational (see Gallagher, 2010) segregation on the basis of religious affiliation. In contrast to Israel, large segregated population centers do not exist in Northern Ireland. Instead, the pattern is 
one of micro-segregation such that in urban settings entirely Catholic neighborhoods can abut entirely Protestant ones (see Lloyd \& Shuttleworth, 2012). Consistent with this pattern of segregation, there is evidence that children begin to internalize the ethnic-religious symbols and culture of their respective community from three years of age; by age six they already personally identify with their own community and show prejudice (Connolly, 2011; Connolly, Kelly \& Smith, 2009; Connolly, Smith \& Kelly, 2002).

Like Israel, there are integrated and segregated schools in Northern Ireland. The vast majority of children in Northern Ireland attend either State “controlled” schools which are run by the Department of Education Northern Ireland, have formal links to Protestant denominations, and average fewer than 5\% Catholic students, or Catholic “maintained” schools which are overseen by a separate body and average less than 1\% Protestant students (Northern Ireland Council for Integrated Education, 2007). Although both controlled (Protestant) and Catholic maintained schools provide homogenous ethno-religious environments via de facto segregation by religion, there are also integrated schools in Northern Ireland explicitly established to introduce peace education and teach children to respect and value diversity in others by bringing together Catholic and Protestant children. At present only about 5\% of both nursery and primary schools in Northern Ireland are integrated (Department of Education, Northern Ireland, 2015; for reviews see, Gallagher, 2010; Hewstone et al, 2005).

In the following five studies (along with a meta-analysis), we examine the development of essentialist thinking about social categories in Northern Ireland. In our first study, we use a forced-choice inference task based on that used by Birnbaum et al. (2010) to examine the relative potency of a culturally salient social dimension (religion) in guiding inferences about unfamiliar 
properties. In the inference task participants learn that an individual, distinguished by its membership of two social categories, possesses a property, and are presented with two further individuals each sharing with the base membership of just one social category. Participants must decide which of the target individuals is most likely to also possess the property. To the extent that participants view the property to be projectible (see Nisbett, Krantz, Jepson \& Kunda, 1983), their decisions provide an indication of their beliefs about category coherence. That is, projectible properties are more likely to be shared by members of coherent categories, and the belief that category members cohere is an important aspect of essentialism (see Gelman, 2003). We address the question developmentally by testing 6, 8, and 10-year-old children. Based on Connolly’s (1999) findings, we estimated that six years is the youngest age at which children in Northern Ireland might possess knowledge of religion categories. Furthermore, the period from 6-11 years is a time previously shown to be associated with important change in children’s beliefs and reasoning about social categories (e.g. see Deeb et al., 2011; Taylor, Rhodes \& Gelman, 2009).

We address questions of the diversity of the educational environment by comparing category-based social inference among children in religiously integrated schools with those in religiously segregated schools. In Studies 2 and 3 we used a modified methodology to compare absolute levels of social inference amongst children attending segregated and integrated schools in Northern Ireland. In Study 4 we used the same method to examine whether the pattern we had observed was specific to Northern Ireland, or whether it also held in a group of children from the US. In Study 5 we used a completely different measure- - the Essentialism Components Questionnaire (Diesendruck \& Haber, 2009)— to examine whether the pattern observed in 
Northern Irish children’s inferences about social categories was an artefact of the category-based inference measures used in Studies 1-4. And finally, we present a meta-analysis of our findings and address relations between neighborhood diversity and patterns of essentialist thinking about religion categories.

In all of the studies to be described here we asked children about three different social dimensions: religion, gender and pet ownership. The last dimension was included as a control; we expected that children would display more essentialist reasoning (Studies 1-4) and stronger essentialist beliefs (Study 5) about gender (boy vs. girl) and religion (Catholic vs. Protestant) categories than about control (hamster owners vs. goldfish owners) categories. Based on the Israeli results, we predicted that children from Northern Ireland will make more inferences based on religion category membership than based on membership of other social categories.

Furthermore, if the Northern Irish case is like the Israeli one, then we should observe essentialist reasoning and beliefs about religion categories amongst the youngest children in our studies, and the effect of attending an integrated school should be to attenuate relatively high and early emerging levels of essentialist reasoning.

\section{Study 1}

\section{Method}

Participants. Participants were 174 children, aged 6-11 years, recruited from State controlled (Protestant), Catholic maintained and Integrated schools in Northern Ireland. As may be seen in Table 1 where we present demographic information about our sample, Ns for each age group in each school type varied between 17 and 20. These Ns are comparable to those in

previous developmental studies of social inference (e.g. Birnbaum et al., 2010). 
Materials and Design. Children were presented with a forced choice inference task (similar to that used by Diesendruck \& HaLevi, 2006 and by Birnbaum et al., 2010), in which they had to choose between two competing categories as a basis for inference. We focused on two contrasting categories within each of three focal social dimensions. The primary dimension of interest was religion, and the categories were Catholic and Protestant, chosen because of their cultural, political and historical salience in Northern Ireland. We also asked about gender (boy/girl) as another social dimension for which categories were likely to have inductive potential. Finally, we utilized the dimension of pet ownership (goldfish/hamster owner) as control categories which we deemed unlikely to support inductive generalizations. By comparing inferences based on potentially meaningful categories of religion and gender to inferences based on these less meaningful categories, we can distinguish between targeted beliefs that specific categories conveyed inductive potential, and more generic beliefs about the inductive potential of (potentially novel) social categories.

Each participant was presented with 12 triads of pictures. Each triad consisted of two base pictures and one target. The base pictures had explicit values on two of the three focal social dimensions: religion (Catholic/Protestant), gender (girl/boy), and pet ownership (goldfish/hamster), and contrasted on two of these dimensions (e.g., a Catholic boy and a Protestant girl). The target matched each base picture on one of the two dimensions (e.g., a Catholic girl). Each pairwise combination of social dimensions (religion-gender, religion-pet ownership, gender-pet ownership) was tested with four triads that utilized every combination of values on the two dimensions as targets. 
Stimuli were 36 hand-drawn pictures of children. Religion and pet ownership were conveyed by verbal descriptions alone; the descriptions conveying religion category membership were “goes to a \{Catholic/Protestant\} church” and conveying pet ownership category membership were “owns a \{goldfish /hamster\}.” Gender category membership was depicted visually based on clothing and hairstyle as well as labels, and conveyed via the labels boy and girl. All children were depicted on similar neutral backgrounds. In triads where the contrasting categories were religion and pet, gender was kept constant. Here and throughout, we chose to convey category membership for religion and pet ownership categories through descriptions rather than labels in order to make the categories as accessible as possible to our youngest participants. Descriptions specify the relevant social dimension (e.g., "goes to X church” is a religious affiliation) in a way that labels (“is an X” is potentially ambiguous) may not.

As is common in the adult literature on category-based induction (see Feeney, Coley \& Crisp, 2010), we used entirely blank properties in order to ensure that any effects we observed were due to participants' beliefs about the categories in the experiment, rather than the framing of the property. In the adult literature, alphanumeric symbols are often used to refer to properties (e.g. property X15). As this was deemed inappropriate for the age range studied here, we instead used a different novel attribute (e.g., is noxy, is flirst) for each triad. The order of presentation of each set of triads and the novel attributes used were counterbalanced across participants.

Procedure. All participants had written parental consent and were tested individually in a quiet area of their school. They were told that we were interested in how children think about others and that there were no right or wrong answers to the questions that they would be asked. Children were then presented with the 12 triads. For an example of a triad contrasting religion 
and control category membership, see Figure 1. As Figure 1 illustrates, children were presented with three pictures - two base pictures and one target picture. When presented with the first base picture the experimenter said (using Figure 1 as an example) "Look at this child here. This child goes to a Catholic church and owns a hamster. This child is flirst.” The second base picture was presented and the experimenter said "Look at this child here. This child goes to a Protestant church and owns a goldfish. This child is legan.” The target was then presented and the experimenter said "Look at this child here. This child goes to a Catholic church like this child (the experimenter points to the first base picture) and owns a goldfish like this child (point to the second base picture). Do you think this child (points at the target) is flirst like this child (points to base picture 1) or legan like this one (points to base picture 2)?” Thus, children were asked to choose between shared membership in the same religion category and shared membership in the same control category when deciding which novel inference to draw. There were no children who were unwilling to make an inference at any point during the task. A score of 1 was given to the category that children based an inference on and a score of 0 was given to the category that children chose not to base an inference on. In addition to the counterbalancing of triads and properties across participants, the order of verbally presenting each of the two categories in each picture was also counterbalanced.

\section{Results}

Scoring. Each child attempted 12 experimental trials and had eight opportunities to make an inference based on each of the three social dimensions used in the experiment. Four of the 12 trials required them to choose between each combination of the social dimensions used in the experiment. For each combination of dimensions we calculated a score out of four to assess the 
degree to which participants preferred to make inferences on the basis of one or other of the dimensions. Because of our focus on inferences based on religion categories, we also calculated a score for each participant corresponding to the total number of religion-based inferences on all trials involving religion (i.e., religion-gender and religion-pet trials), ranging from 0-8.

Relative Importance of Each Social Dimension. To examine whether participants regarded certain social dimensions as a more useful basis for inference than others, we compared mean responses to chance (50\%) for each dimensional pair, both overall and broken down by age and school type. Results are presented in Figure 2.

Religion versus Control. Overall, children made more inferences based on religion than based on pet ownership $(M=2.33$ religion-based inferences, $S D=1.31), t(173)=3.35, \mathrm{p}=.001$, Cohen’s $d=.25$. As depicted in Figure 2A, among children attending State Controlled (Protestant) schools, 6-year-olds did not differ from chance, whereas 8- and 10-year-olds both based inferences on religion categories more often than expected by chance $(\mathrm{t}(19)=2.60$, $\mathrm{p}=0.018, \mathrm{~d}=.58$ and $\mathrm{t}(19)=2.41, \mathrm{p}=0.027, \mathrm{~d}=.54$, respectively). Likewise, for children attending Catholic maintained schools, 6-year-olds were at chance, whereas 8-year-olds showed a significant preference for religion-based inferences, $t(19)=2.89, p=0.009, d=.65$. Although in the same direction, the difference did not reach significance for 10-year-olds attending Catholic maintained schools, $\mathrm{t}(16)=1.10, \mathrm{p}=0.288, \mathrm{~d}=0.2$. In contrast, none of the age groups of children attending integrated schools preferred religion-based inferences over those based on pet ownership. In sum, a preference for basing inferences on religion over control categories seems to emerge around age 8 , and only among children attending religiously segregated schools. 
Religion versus Gender. Overall, children made more inferences based on religion than based on gender, $M=2.60, S D=1.28, \mathrm{t}(173)=6.24, \mathrm{p}<.001$, Cohen's $d=0.47$. As depicted in Figure $2 \mathrm{~B}$, the developmental patterns were very similar to those for religion versus control inferences. Specifically, among children attending State Controlled schools, 6-year-olds did not differ from chance, whereas 8-year-olds showed a significant preference for religion-based inferences over gender-based inferences, $t(19)=4.22, \mathrm{p}<0.001, \mathrm{~d}=.94$. Although in the same direction, the difference did not reach significance for 10-year-olds attending State Controlled schools, $\mathrm{t}(19)=1.69, \mathrm{p}=0.107, \mathrm{~d}=0.38$. For children attending Catholic maintained schools, 6year-olds were at chance, whereas 8- and 10-year-olds both based inferences on religion categories more often than expected by chance $(\mathrm{t}(19)=3.33, \mathrm{p}=0.004, \mathrm{~d}=.74$, and $\mathrm{t}(16)=4.76$, $\mathrm{p}<0.001, \mathrm{~d}=1.15$, respectively). Among children attending integrated schools, neither the 6-yearolds nor the 10-year-olds differed from chance, although 8-year-olds showed a significant preference for inferences based on religion over gender, $\mathrm{t}(19)=2.11, \mathrm{p}=0.049, d=0.47$. In sum, a preference for basing inferences on religion over gender categories seems to emerge around age 8, and was most evident among children attending religiously segregated schools.

Gender versus Control. Overall, to our surprise, children were no more likely to base inferences on gender than on pet ownership, $M=1.87, S D=1.31, \mathrm{t}(173)=1.27, \mathrm{p}=0.205, d=$ .10. As is evidenced in Figure 2C, no subgroup differed from chance on these items.

Effects of Age and Educational Context on Religion-Based Inferences. Because religion was our focal dimension, we conducted an additional factorial ANOVA to examine the effect of educational context (State controlled, Catholic maintained, and Integrated schools), and age group (6-7 years, 8-9 years and 10-11 years) on children's religion based inferences across 
both types of trials (for a total of 8) that involved religion (see Figure 3). We also compared means to chance (4 out of 8 responses.) We observed a significant main effect of age group on children's tendency to make inferences based on shared religion category membership, F(2, 165) $=5.38, \mathrm{p}<.01, \eta^{2}$ partial $=0.06$. Bonferroni-corrected pairwise comparisons revealed that 8-yearolds made significantly more inferences based on religion than did 6-year-olds, whereas 10-yearolds did not differ from either group. Neither the effect of educational context, $\mathrm{F}(2,165)=1.52$, $\mathrm{p}>.2, \eta_{\text {partial }}^{2}=0.02$, nor its interaction with age group, $\mathrm{F}(4,165)=.9, \mathrm{p}>.45, \eta^{2}$ partial $=0.02$, were significant. However, when compared to chance performance (see Figure 3), religion-based inferences exceeded chance levels among 8- and 10-year-olds attending segregated schools (8year-olds: $\mathrm{t} \geq 4.34, \mathrm{p}<.001, \mathrm{~d} \geq .97 ; 10$-year-olds: $\mathrm{t} \geq 2.70, \mathrm{p}<.02, \mathrm{~d} \geq .66$ ), but never did so for children attending integrated schools. Taken together, these results suggest that a preference for basing inferences on religion categories emerges around age 8, and only among children attending religiously segregated schools.

\section{Discussion}

Overall, the children in this study made more inferences based on religion category membership than on gender or control category memberships, and this preference for religionbased inferences emerged with development. Whereas the youngest children did not distinguish between the categories in terms of their inductive potential, by eight years of age religion as more informative than gender or pet ownership for the purposes of inference. This is consistent with the view that religion categories become increasingly essentialized among Northern Irish children, and suggests that essentialist beliefs about religion categories may emerge later in 
Northern Ireland than do essentialist beliefs about ethnicity categories amongst Israeli children (see Birnbaum et al., 2010; Diesendruck \& HaLevi, 2006).

The results also suggest that Northern Irish children’s emerging essentialist beliefs about religion categories may be associated with educational context. Although the ANOVA did not show significant effects of school context, comparisons to chance showed that, amongst children attending integrated schools, religion categories are not used as a basis for inference more than would be expected by chance, and are no more inductively potent than arbitrary control categories. However, for children attending segregated schools, more inferences are based on religion category membership than would be expected by chance from 8 years of age, and by 8 years of age, religion categories are seen as more inductively compelling than control categories, or gender categories. Thus, these findings are broadly consistent with previous findings that educational context is associated with essentialist beliefs about culturally salient social categories (see Deeb et al. 2011). However, the developmental timing and direction of the effects suggests that in Northern Ireland, segregated educational contexts may be associated with an increase in essentialist beliefs about religion categories over time, rather than, as has been found elsewhere, integrated contexts being associated with a decrease in essentialist beliefs. We cannot at present make causal claims about the role of educational context in the emergence of essentialist thinking; in the General Discussion we will consider constraints on how these associations with school context may be interpreted.

Surprisingly, children based inferences on gender at chance levels (although this finding is not without precedent; see Diesendruck and HaLevi, 2006; Taylor \& Gelman, 1993). Coupled with evidence that children perceive gender categories to be highly natural (i.e., immutable and 
non-arbitrary, e.g., Taylor, 1996; Taylor, Rhodes \& Gelman, 2009), these findings may align with Haslam et al.’s (2000) analysis of social essentialism into components of naturalness and cohesiveness. Perhaps children's extensive experience with diverse members of gender categories means that although they believe them to be natural, they perceive them to lack cohesion, and thus to provide a relatively weak basis for inference. We return to this point in Study 5.

Overall, these results provide a basis of comparison for earlier work by Diesendruck and colleagues in Israel (e.g. Birnbaum et al., 2010), and show that when forced to choose, children in Northern Ireland prefer to draw inferences on the basis of religion over gender or control categories. They also suggest that in Northern Ireland the emergence of religion as a privileged category for social inference may be especially pronounced among children attending segregated schools. However, because the task involved a forced choice, we cannot draw inferences from these data about absolute levels of inductive potential afforded by religion categories. In the next study, we introduce a slightly modified task which allows us to do so.

\section{Study 2}

As noted above, in a forced choice paradigm like that used in Study 1 (and by Birnbaum et al., 2010; Diesendruck \& HaLevi, 2006, and others), participants’ responses are taken to indicate which category is considered more inductively potent. One drawback of this methodology is that it cannot measure absolute levels of inference; by constraining the number of inferences children can make, it becomes insensitive to the possibility that both—or neither—of the categories might be seen as inductively potent. To replicate and generalize the findings of Study 1 with a less constrained task, we taught children a novel property about an exemplar (a 
hypothetical child said to belong to two social categories, e.g. Catholic boy), and then individually presented targets that shared both, one, or neither category (another Catholic boy, a Catholic girl, a Protestant boy, a Protestant girl) and asked whether each target would share the property. Because this allowed us to assess absolute levels of inference as well as independently assessing the contributions of different social categories, it permitted us to test for general changes in levels of social essentialism as well as for variations in essentialist reasoning about religion categories specifically. Differences between socially relevant categories and the control category are particularly important with this method which does not require participants to choose between the different social categories as a basis for inference. Thus, observing significant differences between, for example, inferences based on religion versus pet ownership is good evidence that those inferences are based on specific beliefs about religion categories rather than some more generic beliefs about the inductive potential of (possibly novel) categories.

Method

Participants. 165 children, drawn from Catholic maintained, State controlled (Protestant) and Integrated primary schools in Northern Ireland, participated in this study. Table 2 provides a detailed breakdown of numbers, age and religious affiliation for each group.

Materials and Design. We used the same categories in this study as in Study 1, but modified the task, as described above. Each participant was presented with three sets of pictures. Each set contained a base and four targets. The base had explicit values on two of the three focal social dimensions: religion (Catholic/Protestant), gender (girl/boy), and pet ownership (goldfish/hamster owner). The corresponding targets represented all possible combinations of the 
two dimensions. For example (see Figure 4), the religion/gender set involved one trial for which the base and target belonged to the same religion and gender categories $(\mathrm{R}+/ \mathrm{G}+)$, one trial for which they shared religion but differed in gender (R+/G-), one in which they shared gender but differed in religion $\left(\mathrm{R}-/ \mathrm{G}^{+}\right)$, and one in which they came from different religion and gender categories (R-/G-). The category membership of the base was counterbalanced, so the specific role assigned to each target varied accordingly. For instance, the target described as a girl who goes to Catholic church was considered R+/G- for participants presented with a Catholic boy as a base, but R-/G+ for those who were presented with a Protestant girl as a base.

Stimuli were 15 hand-drawn pictures. In this study, as in Study 1, religion and pet ownership category memberships were conveyed by behavioral descriptions only. Accordingly, the five pictures which were used for the religion/pet ownership trials depicted androgynous silhouettes. Gender category membership was depicted visually as well as with a label, and the remaining 10 pictures represented boys or girls (based on clothing and hairstyle).

Procedure. Each child was tested individually for 5-10 minutes in a quiet corner of their school and had full parental consent to participate. Each child was told that they would be shown pictures of children and asked a question about each picture. For each set of categories, the experimenter showed the base picture and verbally presented the appropriate category information, as well as the novel property (gleeve, sproice or chaunch). For example, for the religion/gender set, children might be shown a picture of a girl and told, "Look at this child. This child is a girl and goes to a Catholic church. This child is gleeve.” With the base picture visible, children were then shown each target picture in turn. For each target, the experimenter verbally presented the appropriate category information, and asked whether or not the target would share a 
novel property with the base. For example, children might then be shown a picture of a different girl and told, "Now, look at this child. This child is a girl and goes to a Protestant church. Do you think this child is gleeve like this child (referring to the base)?” For trials involving pet

ownership, the child was said to "have a pet goldfish/hamster.” Children responded “yes” or "no” for each target. The same unfamiliar property was used for all four inferences in each set of trials. Order of presentation of the three sets and the four targets within each set was counterbalanced.

\section{Results}

Scoring. Each child saw 4 base-target pairs that matched on each social category. To measure the degree to which each social category promoted inductive generalization, we calculated 3 scores for each participant, corresponding to the number of times the target was said to share the property with the base (ranging from 0-4) for each type of social category (religion, gender, control). For example, the religion score was the number of positive inferences for the $\mathrm{R}+/ \mathrm{P}+, \mathrm{R}+/ \mathrm{P}-, \mathrm{R}+/ \mathrm{G}+$, and $\mathrm{R}+/ \mathrm{G}-$ items.

Overall Analysis of Social Inference. To examine patterns of social inference, we conducted a 3 (Social Dimension: religion, gender, pet) x 3 (School Group: Catholic maintained, State controlled, integrated) x 3 (Age Group: 6-7, 8-9, and 10-11 year olds) mixed ANOVA on mean inferences to matching targets. Overall, children based more inferences on religion $(M=2.60)$ and the control category $(M=2.41)$ than based on gender $(M=2.04), F(2,312)=22.43$, $p<0.001, \eta^{2}$ partial $=0.13$; Bonferroni-corrected pairwise comparisons revealed the differences between gender and the other two categories to be statistically significant $(\mathrm{p}<.001)$, whereas overall inferences based on religion did not differ from those based on the control category. This was qualified by a significant interaction between social dimension and school, 
$F(4,312)=2.66, p=0.033, \eta^{2}$ partial $=0.03$, depicted in Figure 5. To explore this interaction we carried out three one-way ANOVAs comparing children's use of religion, pet, and gender categories to guide inferences separately for each type of school. Children in Catholic maintained and state controlled schools showed similar patterns of inference; for both groups, inferences based on religion and control categories were more frequent than those based on gender (Catholic maintained: $\mathrm{F}(2,106)=11.17, \mathrm{p}<.001, \eta^{2}$ partial $=0.17$; state controlled: $\mathrm{F}(2,110)=$ 14.68, $\mathrm{p}<.001, \eta^{2}$ partial $=0.21$, Bonferroni-corrected $\mathrm{p}<.001$ ), whereas inferences based on religion did not differ from those based on control categories. In contrast, inferences for children attending integrated schools did not differ by social dimension, $F(2,108)=1.68, p=.19$, $\eta^{2}$ partial $=0.03$.

The results of the omnibus ANOVA also revealed a marginally significant interaction between category and age, $F(4,312)=2.09, \mathrm{p}=.08, \eta^{2}$ partial $=0.03$, depicted in Figure 6 . To explore this interaction we carried out three one-way ANOVAs comparing children's use of religion, pet, and gender categories to guide inferences separately for each age group. These revealed that 6- and 8-year-olds made more inferences based on religion and control category memberships than based on gender (6-year-olds: $\mathrm{F}(2,104)=7.29, \mathrm{p}=.001, \eta^{2}$ partial $=0.12$; 8-yearolds: $\mathrm{F}(2,118)=12.33, \mathrm{p}<.001, \eta^{2}$ partial $=0.17$; Bonferroni-corrected $\left.\mathrm{ps}<.005\right)$. For both groups, inferences based on religion did not differ from those based on control categories. In contrast, the pattern for 10-year-old children was quite different; these children made significantly more inferences based on religion than on either of the other categories, $F(2,102)=7.11, p=.001$, $\eta^{2}$ partial $=0.12$, Bonferroni-corrected $\mathrm{p}<.05$. For 10 -year-olds, inferences based on gender did not differ from those based on control category membership. 
Religion-based inferences. Although the omnibus 3-way interaction was not significant $\left(F(8,312)=1.00, p=.434, \eta^{2}\right.$ partial $\left.=0.02\right)$, we conducted exploratory analyses to examine our focal question about the emergence of religion categories as privileged guide for social inferences. Specifically, we compared religion-based inferences to control (pet ownership-based) inferences for each age/school group via t-test. Difference scores are depicted in Figure 7 (positive scores represent more inferences to religion matches than control matches). Results suggest that religion-based inferences exceeded control inferences for 8-year-olds in state controlled schools $(t(20)=2.55, p=0.019, d=1.14)$ and for 10 -year-olds in Catholic maintained schools $(t(17)=2.56$, $\mathrm{p}=0.020, \mathrm{~d}=1.24)$. Religion-based inferences never exceed control inferences among children in integrated schools.

\section{Discussion}

The results of this study suggest that in the absence of a forced choice, Northern Irish children’s preferences for religion-based inferences are still late-emerging and influenced by school context. Specifically, results suggest that preference for religion-based inferences over control inferences was only observed among 10-year-olds, but not among 8- or 6-year-olds. Likewise, results suggest that preference for religion-based inferences over control inferences were only observed among children in segregated schools (10-year-olds in Catholic maintained schools, and 8-year-olds in state controlled schools) but not for children in integrated schools, who showed no differential use of religion, gender, or pet ownership to guide inferences. These results add weight to the possibility, suggested by Study 1, that children in Northern Ireland do not develop essentialist beliefs about religion categories until considerably later than had been suggested by results from the Israeli case study of ethnicity categories, and that attendance at a 
segregated school may be associated with an emerging preference for religion-based inferences.

The results of Studies 2 were somewhat weaker than those of Study 1, and suggest somewhat different conclusions about the age at which essentialist reasoning about religion categories emerges in Northern Ireland. In Study 1, religion emerged as a privileged basis for inferences around age 8, whereas in Study 2 we did not observe a significant difference between religion- and control-based inferences until age 10. For these reasons, we decided to repeat Study 2, making a change to the materials. We reasoned that the absence of visual cues to religion and pet ownership categories may have taxed the working memory resources of younger participants, thus leading them to fail to distinguish between these categories in terms of inductive potency. Accordingly in Study 3 all social dimensions were represented visually as well as with behavioral descriptions (religion and control) and verbal labels (gender).

\section{Study 3}

The aim of Study 3 was to establish whether Northern Irish children begin to treat religion category membership as a particularly informative basis for social inference at eight years of age (as suggested by the results of Study 1) or ten years of age (as suggested by Study 2). We used the same basic method as in Study 2 but, in order to make the task cognitively less demanding for participants, in Study 3 we included visual cues to category membership. We hypothesized that this might lead to participants distinguishing religion and control categories earlier than was observed in Study 2. 


\section{Method}

Participants. A total of 228 Northern Irish children, drawn from Catholic maintained, State controlled (Protestant), and integrated schools participated in this study. Table 3 provides a detailed breakdown of numbers, age and religious affiliation for each group.

Materials and Procedure. We used materials similar to those used in Studies 1 and 2. However, in this study, category membership was conveyed by verbal labels and by pictorial representations: for religion, one of two visually distinct churches was depicted in the background, for gender, the child was depicted as a boy or a girl (based on clothing and hairstyle), and for pet ownership, a drawing of a hamster or goldfish was presented next to the depicted child (see Figure 8). For religion/pet trials (i.e., those for which no gender value was specified), we used androgynous silhouettes to depict the base and target children. The procedure was identical to that used in Study 2.

\section{Results}

Scoring. As in Study 2, each child saw 4 base-target pairs that matched on each social category. To measure the degree to which each social category promoted inductive generalization, we calculated 3 scores for each participant, corresponding to the number of times the target was said to share the property with the base (ranging from 0-4) for each type of social category (religion, gender, control).

Overall Analysis of Social Inference. To examine patterns of social inference, we conducted a 3 (Social Dimension: religion, gender, pet) x 3 (School Group: Catholic maintained, State controlled, integrated) x 3 (Age Group: 6-7, 8-9, and 10-11 year olds) mixed ANOVA on mean inferences to matching targets. Overall, as in Study 2, children made more inferences based 
on religion $(M=2.81)$ and the control category $(M=2.46)$, than on gender $(\mathrm{M}=2.06), F(1.9$, 411.9) $=55.07, p<0.001, \eta^{2}$ partial $=0.20$; unlike in Study 2, overall inferences to religion categories were higher than those to control categories (all differences significant at $p<0.01$ via Bonferroniadjusted t-test).

This was qualified by a marginal interaction between Category and Age Group, $F(3.8$, 411.9)=2.36, $p=0.06, \eta^{2}$ partial=0.02 (shown in Figure 9). To explore this interaction we again carried out three one-way ANOVAs comparing children's use of religion, pet, and gender categories to guide inferences separately for each age group. Results suggest that each age group presented a unique profile regarding differences among specific social dimensions. For 6-yearolds, inferences based on religion and control categories were equivalent, and more frequent than inferences based on gender $\left(F(2,144)=31.44, p<0.001, \eta^{2}\right.$ partial $=0.30, p<0.001$ via Bonferronicorrected t-tests). Eight-year-olds made more inferences based on religion than based on the control categories, which in turn were more frequent than those based on gender $\left(F(2,154)=21.52, p<0.001, \eta^{2}\right.$ partial $=0.22, p<0.05$ via Bonferroni-corrected t-tests $)$. Finally, for 10 year-olds, inferences based on religion were more frequent than inferences based on control categories or gender, which did not differ $\left(F(2,152)=11.91, p<0.001, \eta^{2}\right.$ partial $=0.14, p<0.02$ via Bonferroni-corrected t-tests). There were no significant effects involving educational context, and the three-way interaction was also not significant.

\section{Discussion}

Overall, participants in this study based more inferences on religion category membership than membership in other social categories. Thus, we have replicated the central finding of Study 1, that children in Northern Ireland view religion categories as a strong basis for social inference. 
Furthermore, just as in Study 1, 6-year-olds did not distinguish between the inductive potential of religion and control categories, whereas 8-year-olds did so. In other words, religion categories did not become a uniquely important basis for social inference until eight years of age. This suggests that the finding in Study 2, that children did not distinguish between religion and control categories as bases for inference until 10 years of age, may have been due to the absence of visual cues in that study making the task more demanding on memory. However, because we did not experimentally manipulate this aspect of our materials, this is a speculative interpretation. Interestingly, even the addition of visual cues in this study did not lead to 6-7 year olds distinguishing between the categories. Thus, the results of this study, along with the results of Study 1, suggest that in contrast to Israel where children appear to arrive at school with essentialist beliefs about ethnic categories, children in Northern Ireland do not develop such beliefs about religion categories until eight years of age.

In contrast to the results of Studies 1 and 2, the results of this study show no clear differences between children attending integrated schools in Northern Ireland and those attending segregated schools. Both make more inferences based on religion category membership than based on gender or membership in a control category. We return to this issue in the General Discussion.

\section{Study 4}

Studies 1-3 present clear evidence that by age 8, children in Northern Ireland come to essentialize religion categories to a greater degree than gender or control categories. Although the historical and cultural significance of the categories Catholic and Protestant in Northern Ireland is undisputed, this developmental pattern may be specific to the historical factors that 
have shaped Northern Ireland culture, or alternatively may represent a more general tendency to essentialize religion categories. To begin to distinguish between these possibilities, we examined whether the pattern of development we see in Studies 1-3 is specific to Northern Ireland, by testing a comparison group of children from the greater Boston area in the US. We chose to recruit a sample in Boston because of the geographical distance and the cultural similarities. People in the Boston area share close linguistic, cultural and even family linkages to Northern Ireland, and thus in many respects the two areas are culturally very similar, and thus comparable in many ways. In particular, the largest religious group in both places is Catholic; c. 29\% of people declare themselves Catholic in Boston (Pew Research Centre, 2014), versus c. 41\% in NI (Northern Ireland Statistics and Research Agency, 2014). However, the geographical distance and lack of conflict between Protestants and Catholics in the US means that children in Boston are less likely to be affected by the historical-cultural conflict specific to Northern Ireland than children in, say, Great Britain or the Republic of Ireland. Therefore, if the historical-culturalcontext specific to Northern Ireland is driving the pattern of emergence of essentialist thinking about social categories we observe there, then the categories Catholic and Protestant, although present and familiar to most Americans, may be less salient—and perhaps less essentialized_than they are in Northern Ireland.

\section{Method}

Participants. A total of 67 children, drawn from public schools in the Commonwealth of Massachusetts, USA, participated in this study. Thirty of these children were aged 6-7 years, 28 were aged 8-9 years and 23 were aged 10-12 years. Twenty nine percent of the sample was Catholic, 12\% Protestant, 5\% other or mixed and the remaining 53\% were not religious. With 
respect to race and ethnicity, the communities from which the sample was drawn averaged $90 \%$ European American, 2\% African American, 5\% Asian American, and 4\% Latino, according to 2010 US Census figures. These categories are more varied than those which characterize the samples from Northern Ireland, which were close to 100\% Caucasian Europeans.

Materials and Procedure. With one exception, the materials were identical to those used in Study 3 where participants received both pictorial and verbal cues for each category they were presented with. Because we had identified religion and pet ownership category memberships using verbal cues only in Studies 1 and 2, but using verbal and pictorial cues in Study 3, half of the participants in Study 4 received pictorial plus verbal cues, and half received verbal cues for all three dimensions but pictorial cues for gender only (i.e., religion and pet ownership were described but not pictured). This was done to test whether responses were influenced by the presence of the pictorial representations of religion and pet categories ${ }^{1}$. In all other respects the procedure and data scoring was as described for Study 3.

\section{Results and Discussion}

Mean rates of inference for US children, broken down by age and social dimension, are presented in Table 4. We computed mean scores for inferences based on religion, gender, and control categories as described for Studies 2 and 3, and conducted a 3 (Age Group) x 3 (Social Dimension) mixed ANOVA. Overall, inferences to religion and control categories were higher than those to gender categories, but did not differ from each other, $F(2,128)=9.62, \mathrm{p}<.001$, $\eta_{\text {partial }}^{2}=0.13$, Bonferroni corrected t-test ps $<0.005$. Although no other effects were significant, comparisons to chance performance (see Table 4) revealed that inferences based on religion and

${ }^{1}$ Analysis of this manipulation revealed no effect of materials so, for the purposes of subsequent statistical analysis, we ignored this variable. 
control category membership were above chance for 6-year-olds, marginally above chance for 8year-olds, and did not differ from chance for 10-year-olds. Gender-based inferences never differed from chance levels.

Although this is a preliminary foray into cross-national comparisons of reasoning about religion categories, based on qualitative comparison the US children in this study differ markedly from children in Northern Ireland in several ways. First, children in the Boston area never drew inferences based on religion at levels that exceeded the control category, whereas children in Northern Ireland did so by age 8 (Studies 1 and 3) or 10 (Study 2). Second, only 6-year-olds, but not 8- or 10-year-olds, drew inferences based on any social category at above-chance levels, whereas in Northern Ireland, the developmental trajectory was reversed, from chance levels around age 6 to above-chance levels among older children. Moreover, the differences were specific to the salience of religion categories; inferences based on gender were similarly rejected by children on both sides of the Atlantic. These results suggest that the pattern we have observed in Northern Irish children's reasoning about religion categories is not universal, but instead is likely related to historical and cultural factors specific to Northern Irish society.

An alternative explanation for the different patterns in the US and Northern Ireland is that US children simply lack familiarity with the labels Catholic and Protestant. Although we are aware of no data directly investigating the familiarity of religion category labels to US children, previous work suggests that children in Northern Ireland identify with their ethnic-religious category by age six (see Connolly, 2011), and that US participants retrospectively report acquiring the term Catholic at 7-8 years of age (Kuperman, Stadthagen-Gonzalez \& Brysbaert, 2012). As such, it seems unlikely that our 10-year-old US participants--who showed no evidence 
of a preference for inferences based on religion category membership--are completely unfamiliar with these labels. Nevertheless, until familiarity data are collected, the possibility remains that the difference between children in Northern Ireland and the US may be due to relative familiarity with the category labels, rather than differences in essentialist thinking about religion categories.

\section{Study 5}

The results of Studies 1-4 are remarkably coherent and suggest that essentialist beliefs about religion categories emerge relatively late in Northern Ireland, and are more likely to be observed amongst children attending segregated rather than integrated schools. As discussed above, this pattern is somewhat different from that described by other researchers (e.g., Diesendruck and colleagues). These differences may reflect contextual and cultural differences in the manifestation of essentialist thinking about social categories. However, the different findings may also stem from methodological differences. For example, whereas Diesendruck and colleagues asked participants to reason about specific novel properties (e.g. “likes to play zigo”), we asked children to reason about properties presented as adjectives (e.g. “is legan”). As such, one possibility is that essentialist reasoning in our study showed a different developmental pattern because younger children may not have taken the adjectives to indicate projectible properties. Although we think this is unlikely given the willingness of 6-year-olds in the US to draw inferences about identical properties, and moreover, this methodological difference doesn't explain the school- or dimension-based differences among older children, it is nevertheless a systematic methodological difference that warrants attention.

In addition, whereas Diesendruck and colleagues always conveyed social category membership via labels (e.g., "this child is a boy”), we used behavioral descriptions for religion 
and pet categories (e.g. "this child goes to a Catholic church”), and used category labels for gender categories only. As such, one possible explanation for the late emergence of essentialist thinking about religion categories in our study is that membership in religion and pet categories had to be inferred from behavioral descriptions. In other words, conveying category membership via descriptions rather than labels may underestimate the inductive power of these categories for younger children (see Gelman, Collman \& Maccoby, 1986). Importantly, this possibility is weakened by the observation that gender categories - the only categories whose membership we actually did convey via labels_-were consistently the weakest basis for inductive generalizations. Nevertheless, given these possibilities, it is important to assess the generality of our results using a different measure of essentialism.

In Study 5 we sought to examine essentialist thinking about social categories in Northern Ireland using an entirely different measure. To do so, we used a modified version of the Essentialism Components Questionnaire, which has previously been used to assess essentialist beliefs in children as young as five (Deeb et al., 2010; Diesendruck \& Haber, 2009). Specifically, we used items designed to examine the degree to which children view social categories as distinct from each other (i.e., having strong and well-defined boundaries), and stable (i.e., resistance to change). Both of these measures can be thought of as indices of category naturalness rather than of category coherence (e.g., Haslam et al., 2000). To the extent that this measure corroborates the results reported above- that older children show more evidence of essentialist beliefs about religion categories than younger children, and that such beliefs are most pronounced amongst those attending segregated schools - it becomes less likely that our inference results are due to methodological artefacts. 


\section{Method}

Participants. 94 children were recruited from Catholic maintained and integrated primary schools in Northern Ireland. As may be seen in Table 5 where we present demographic information about our sample, Ns for each age group in each school type varied between 15 and 16. These Ns are comparable to those in previous developmental studies involving the Essentialism Components Questionnaire (e.g. Diesendruck and Haber, 2009).Written parental consent was given for every child who participated.

Materials and Procedure. Each participant was tested for 10 minutes in a quiet area of their school/classroom. Participants were asked a series of questions about religion, gender, and pet ownership categories. Questions were blocked by dimension, and at the start of each block participants were shown two hand drawn pictures, similar to those used in Studies 2 and 3, and told that each depicted a member of one or other of the social categories assessed by the subsequent questions. For each target dimension, five questions were designed to assess the extent to which participants viewed social categories as distinct and two to assess the extent to which category membership was viewed as stable. All five distinctiveness questions and one stability question were taken from Diesendruck and Haber’s (2009) Essentialism Components Questionnaire. The distinctiveness questions concerned the extent to which members of named social categories (e.g. Catholic and Protestant) are different in what they like, how they behave, how they look, what they have inside their body and what they think. The stability questions asked about the possibility of changing one’s membership from one category to another and whether one can belong to both categories at once. 
We counterbalanced the order in which the three social dimensions were presented, and within blocks participants answered all of the distinctiveness questions before they answered questions about stability. Distinctiveness questions were asked in one of six different orders and the order of the two stability questions was counterbalanced. Distinctiveness questions were phrased “How much are Catholic children and Protestant children different in...” and malleability questions were phrased "How possible is it for a child who owns a goldfish to swap it for a hamster?” Children answered all questions on a visual analogue scale with four response options. Each response option depicted a stick figure the position of whose arms corresponded to the labels “not at all”, “a little”, “a lot”, or “completely”. For example, in the picture illustrating the "not at all” response option, the stick figure’s arms rested together on a surface, whereas in the picture illustrating the "completely” response option, the arms were aloft and held as wide apart as possible.

\section{Results}

Exploratory Factor Analyses. We entered children's responses into three separate factor analyses_-one for each social dimension. All three analyses employed varimax rotation and a principal components extraction method. Factor solutions for religion and pet ownership were identical, producing two factors with eigenvalues above 1 . The first factor, distinctiveness, consisted of responses to the distinctiveness questions, and the second factor, stability, of responses to the stability questions. For religion, the first factor accounted for $34 \%$ of the variance, and the second for $17 \%$ of the variance (for rotated factor loadings, see Table 6 ). For pet ownership, the factors accounted for $33 \%$ and $19 \%$ of the variance, respectively. The initial factor analysis of gender resulted in three factors with eigenvalues greater than 1 . To enable 
between-dimension comparisons we limited the solution to two factors. The first factor, distinctiveness, accounted for $30 \%$ of the variance and the second, stability, for $23 \%$ of the variance.

Based on the factor analyses, we used the raw scores to calculate each child's perceived distinctiveness and stability scores by averaging their responses for each set of items. Stability scores were derived from reverse-scored stability questions so that higher scores represented more essentialist (i.e., less malleable, or more stable) responses. These scores were analysed separately via 3 (Age Group) x 2 (School) x 3 (Dimension) ANOVAs with repeated measures on the last factor.

Category Distinctiveness. Overall, children believed that gender categories $(\mathrm{M}=2.73)$ were more distinct than religion (M=2.39) or pet ownership ( $\mathrm{M=2.44)}$ categories, which did not differ, $\mathrm{F}(2,176)=17.99, \mathrm{p}<.001$, $? \eta^{2}$ partial $=.17$, Bonferroni-corrected t-test $\mathrm{p}<0.001$. However, as may be seen in Figure 10, these differences emerged over development (Age Group $x$ Dimension interaction: $F(4,176)=4.45, p=.002$, 目 $\eta^{2}$ partial $\left.=.09\right)$. To explore this interaction, we conducted three 2 (School) x 3 (Dimension) ANOVAS. These showed increasing differentiation between dimensions with age: 6-year-olds did not distinguish among the dimensions with respect to distinctiveness $\left(F(2,60)=0.76, p=0.472\right.$, ? $\eta^{2}$ partial $\left.=.02\right)$, whereas for 8-year-olds, gender categories were more distinctive than religion categories (although neither differed from pet ownership categories), $\mathrm{F}(2,56)=4.64, \mathrm{p}<.02$, ? $\eta^{2}$ partial $=.14$, and for 10-year-olds, gender categories were seen as more distinct than religion or pet ownership categories, which did not differ $\left(\mathrm{F}(2,60)=29.34, \mathrm{p}<.001\right.$, ? $\eta^{2}$ partial $=.49$. 
Category Stability. Overall, children believed that gender categories $(M=3.16)$ were more stable than religion categories $(M=2.77)$ which were more stable than pet ownership categories $(\mathrm{M}=2.36), \mathrm{F}(2,176)=20.86, \mathrm{p}<.001$, ? $\eta^{2}$ partial $=.19$, Bonferroni-corrected t-tests $\mathrm{p} \leq 0.003$. However, this was qualified by a significant interaction with Age Group, $F(3.6,158.8)$ $=7.2, \mathrm{p}<.001$, ? $\eta^{2}$ partial $=.14$ (see Figure $11 \mathrm{~A}$ ), and a marginally significant interaction with School, $\mathrm{F}(1.8,158.8)=2.76, \mathrm{p}<.08, \eta^{2}$ partial $=.03$ (see Figure 11B). To explore these interactions, we conducted three 2 (School) x 3 (Dimension) ANOVAS. These again showed increasing differentiation between dimensions with age. Six-year-olds did not distinguish among the dimensions with respect to stability $\left(\mathrm{F}(2,60)=1.81, \mathrm{p}=.17\right.$, ? $\eta^{2}$ partial $\left.=.06\right)$ nor did 8-yearolds, $\mathrm{F}(1.5,42.2)=2.5, \mathrm{p}=.11$, $2 \eta^{2}$ partial $=.08$. In contrast, for 10 -year-olds, gender was significantly more stable than religion, which was more stable than pet ownership, $\mathrm{F}(2,60)=$ 67.11, $\mathrm{p}<.001$, ? $\eta^{2}$ partial $=.69$, Bonferroni-corrected t-tests $\mathrm{p}<0.001$. Moreover, this difference was qualified by a significant Dimension x School interaction, $F(2,60)=8.45, \mathrm{p}=.001$, ? $\eta^{2}$ partial $=.22$. Bonferroni-corrected t-tests on the means involved in the interaction revealed that for all 10-year-olds, membership in gender categories was more stable than membership in religion or pet ownership categories $(\mathrm{p} \leq .008)$. However, for children attending segregated schools, religion was seen as more stable than pet ownership $(\mathrm{p}<0.001)$, whereas for children attending integrated schools, stability for religion and pet ownership categories did not differ $(p=0.217)$.

\section{Discussion}

The results of this study are important for two reasons. First, they provide additional support - using an entirely different method - for the claim that essentialist beliefs about religion categories are relatively late-emerging in Northern Irish children, and are more likely to emerge 
in those attending segregated rather than integrated schools. Whereas 10-11 year olds attending segregated schools perceived religion category membership to be significantly more stable than control category membership, 10-11 year olds attending integrated schools did not distinguish between the stability of religion and control categories. This supports the findings of studies 1-3 and makes it unlikely that differences in the developmental pattern seen by us in Northern Ireland and by Diesendruck and colleagues in Israel stem from methodological issues.

Second, these results address the surprising lack of gender-based inferences in Studies 14. In those studies, children consistently made more inferences based on pet ownership categories—chosen as a control because we did not expect them to be essentialised—than gender categories. We argued above that this finding (see also Diesendruck and HaLevi, 2006; Taylor \& Gelman, 1993), coupled with evidence that children perceive gender categories to be highly natural (e.g., Taylor, 1996; Taylor, Rhodes \& Gelman, 2009), is consistent with Haslam et al.’s (2000) analysis of social essentialism into components of naturalness and cohesiveness. Haslam et al. (2000) have demonstrated that adults' essentialist beliefs factor into two orthogonal dimensions: naturalness and cohesiveness (“entitativity;” see also Rangel \& Keller, 2011). The naturalness dimension includes beliefs about the extent to which any social category is 'real' rather than conventional, heritable, and stable over time despite environmental influences. The cohesiveness dimension refers to beliefs about the extent to which category members are homogeneous and share an underlying similarity that is predictive of further observable or hidden properties. Results of Study 5 demonstrate that children in Northern Ireland do indeed hold essentialist beliefs about gender categories. Specifically, gender categories were clearly perceived to be more stable and more distinct than religion or pet ownership categories. Taken 
together with the results of Studies 1-4, these findings suggest that children may essentialize gender categories with respect to naturalness more so than with respect to cohesiveness. More generally, these results also emphasize the importance of analysing the development of essentialist thinking in terms of distinct components (Haslam et al., 2000).

Although gender categories were essentialised in terms of beliefs about distinctiveness and stability, religion categories were essentialised in terms of stability only. We are unsure why this pattern emerged. One interpretative difficulty lies in relating the concept of distinctiveness to Haslam et al's two-factor structure. Indeed, previous work using the ECQ links distinctiveness items both to the sharpness of boundaries between categories (Diesendruck \& Haber, 2009) which is an element of naturalness, and to category uniformity and informativenesss (Deeb et al., 2011), which is an element of coherence. In our view, distinctiveness relates to discrete boundaries between categories rather than to category uniformity. In particular, the distinctiveness questions ask about differences between members of different categories rather than the similarities between members of the same category which might underlie belielfs about informativeness. Another issue with the distinctiveness dimension is that close inspection of factor loadings across the different studies in the literature reveals that individual distinctiveness items have been found to load onto different dimensions. Perhaps the safest interpretation of our findings across all five studies is that they suggest that gender categories are essentialised along the naturalness but not the coherence dimension, whereas religion is essentialised along the coherence dimension and along some, but not all, elements of the naturalness dimension. Why the different elements of the naturalness distinction might be dissociated for religion categories will be a question for future research. 


\section{Meta-analyses}

Overall, results consistently suggest that essentialist beliefs about religion develop relatively late among children in Northern Ireland. Results also suggest effects of school context-that essentialist thinking about religion categories is predominantly observed among children attending segregated schools--but evidence from individual studies is less consistent. In order to examine this potential context effect with more power, we carried out meta-analyses on the results of Studies 1, 2, 3 and 5, using participating schools as the unit of analysis. An advantage of this data analytic strategy is that it also allowed us to examine the effect of community diversity on our measures of essentialist reasoning and beliefs.

\section{Effects of School Type on Essentialist Reasoning}

A total of 20 schools participated in Studies 1, 2, 3, and 5. Six of the participating schools were integrated and 14 segregated. To conduct the meta-analysis, for each participating school we entered the mean difference (and associated standard error) between religion and pet ownership scores on the measure of essentialism administered to participating children (difference between religion inferences and chance responding on the trials placing religion and control category memberships into conflict in Study 1; difference between religion and pet ownership inferences in Studies 2-3 and religion and pet ownership essentialism scores in Study 5) into the Comprehensive Meta-analysis software package (Bornstein, Hedges, Higgins \& Rothstein, 2009). Results of the analysis are presented in Table 7. Mixed effect meta-analysis with schools grouped by type, revealed that overall, essentialist reasoning was more evident for religion categories than control categories (std mean difference $=.27, \mathrm{SE}=.05,95 \% \mathrm{CI}=[.19$, $.36], \mathrm{Z}(20)=6.02, \mathrm{p}<.001)$. Importantly, this category effect was highly significant for 
segregated schools $($ std mean difference $=.30, \mathrm{SE}=.05,95 \% \mathrm{CI}=[.20, .40], \mathrm{Z}(14)=6.00, \mathrm{p}$

$<.001$ ). In contrast, the effect fell short of significance for integrated schools (std mean

difference $=.15, \mathrm{SE}=.11,95 \% \mathrm{CI}=[-.07, .37], \mathrm{Z}(6)=1.34, \mathrm{p}=.18)$, although a test for

hetereogeneity between school types was non-significant, $Q(1)=1.56, \mathrm{p}=.21$. This reinforces

the pattern of results across our experimental studies: religion categories were preferentially

essentialised among children attending segregated schools, but not among children attending integrated schools.

\section{Effects of Community Diversity on Essentialist Reasoning}

An alternative explanation for the effect of school type on essentialist reasoning about religion categories is that perhaps integrated schools tend to be in more integrated neighborhoods than segregated schools, and the diversity of the neighborhood, rather than the diversity of the educational setting, is really driving the differences in essentialist thinking. To examine the relationship between community diversity and essentialist thinking about religion categories, we used census data (Northern Ireland Neighbourhood Information Service, 2012) to estimate the absolute difference between the proportion of Protestants and Catholics in the electoral ward where each of the participating schools was located. Electoral wards in Northern Ireland range in size from approximately 1000 to 9000 inhabitants. Because we did not ask participants for their addresses, we cannot be sure that they lived in the electoral ward where the school was located. However, proximity to the school is a selection criterion for many Northern Irish schools, so primary school children in Northern Ireland tend to go to a nearby school. Thus, a measure of local community homogeneity based on school location is likely to be a good measure of the degree to which participating children’s local communities are diverse. 
In principle, community diversity scores could range from 0 (equal proportions of Catholic and Protestants in the Ward) to 100 (the ward is entirely Catholic or Protestant); in practice, scores ranged from 0.05 to 86.4. The average diversity scores were $29.0($ S.D. $=20.27)$ for wards in which integrated schools were located, and 43.2 (S.D. = 26.41) for wards in which segregated schools were located. Although this difference was not statistically significant, $\mathrm{t}(19)=$ $1.17, \mathrm{p}=.26, \mathrm{~d}=.60$, the size and direction of the effect suggests that integrated schools tend to be located in more diverse communities. Accordingly, it is important to assess in a meta-analysis whether local community diversity offers a plausible alternative account of the effects of educational diversity we have observed.

If community diversity does explain our results, we would expect the highest degrees of essentialist thinking among children attending schools in the least diverse neighbourhoods. To examine this possibility, we carried out a meta-regression analysis to test whether community diversity predicted effect size across our schools and studies. The results in Table 8 suggest that community diversity is unrelated to children’s tendency to essentialise religion categories (regression coefficient $=0.002$ ). Figure 12 clearly illustrates that the measure of community diversity does not predict the size of the category effect, suggesting that the differences between integrated and segregated schools observed in our studies are not attributable to differential diversity of the communities surrounding the schools.

\section{General Discussion}

Our purpose was to carry out a case study of the development of children's essentialist thinking about religion categories in Northern Ireland. Results paint a consistent picture of the development of essentialist thinking among Northern Irish children, and one that differs 
considerably from our expectations. In Study 1, using a forced choice task, we found that 6-yearolds did not discriminate between the inductive potency of religion and control category membership, but that 8- and 10-year-old children did so. In Study 2 we employed a method which permitted children to base individual inferences on membership of more than one category, and found that they did not regard religion category membership as a better basis for social inference than membership in a control category until 10 years of age. The results of Study 3 suggested that children distinguish between religion and control category memberships at eight years. As the willingness to base inferences about individuals on the basis of their category membership depends on beliefs about category cohesiveness, these results strongly suggest that children in Northern Ireland come to privilege religion categories to guide inferences about novel properties, but that such essentialist reasoning about religion categories in Northern Ireland is relatively late-emerging, and is not observed until (at least) eight years of age. The results of Study 5, in which we directly measured essentialist beliefs about social categories, showed that children do not rate religion categories more stable than control categories until 10 years of age. Obtained using an entirely different method, this finding confirms our conclusions about the timing of the emergence of essentialist reasoning and beliefs about religion categories amongst Northern Irish children.

Our results also revealed differences in the essentialist reasoning of Northern Irish children educated in integrated and segregated schools. In Study 1 we found that children educated in segregated Catholic maintained or State controlled (Protestant) schools perceived religion categories to be more inductively potent than control categories by age 8 , whereas children educated in integrated schools did not differentiate among social dimensions with 
respect to inductive potential even at age 10. Similar results were obtained in Study 2. Although the results of Study 3 did not replicate this pattern, the tendency to believe membership of religion categories to be more stable then membership of control categories was only observed in 10 year olds attending segregated schools in Study 5. Thus, the overall picture that emerges is of essentialist beliefs about religion categories emerging predominantly in children attending religiously segregated schools. The majority of children in our studies who attended integrated schools showed no evidence of more essentialist reasoning about religion categories than about control categories. These conclusions were confirmed by the results of a meta-analysis across the results from all participating schools in Northern Ireland, which also ruled out neighborhood diversity as an alternative explanation for this finding. Thus, in Northern Ireland, selective essentialist thinking about religion categories emerges among children attending religiously segregated schools, but not among children attending religiously integrated schools.

The results of Study 4 showed, as expected, that children in the US do not appear to engage in more essentialist reasoning about religion categories than other social categories. In fact, the pattern we observed amongst children from the US in Study 4 was, in many respects, the reverse of the pattern observed in Northern Irish children in Study 1. Northern Irish children showed no evidence of essentialist reasoning until eight years of age, whereas children in the US showed evidence of essentialist reasoning at age six — perhaps due to category novelty—but no evidence of essentialist reasoning at eight or 10 years of age. This is consistent with the idea that the developmental pattern regarding essentialist reasoning about religion categories we observed in Northern Ireland may be specific to the particular historical, political, and cultural context of Northern Ireland. 


\section{Comparing Northern Ireland and Israel}

We sought to generate a Northern Irish case study of the development of essentialist reasoning about religion categories in part to complement the research program of Diesendruck and colleagues on the development of essentialist thinking about ethnicity categories in Israel (e.g. Birnbaum et al., 2010, Diensendruck \& HaLevi, 2006). It is important to point out that there are multiple important differences between the Northern Irish and Israeli case studies, and as earlier discussion of our methodological choices will have made apparent, our intention was not to replicate the Israeli studies in Northern Ireland. Nevertheless, a qualitative comparison of overall developmental patterns in the two cases is highly informative; it reveals striking parallels as well as important differences in development of essentialist thinking in the two contexts, and raises generative questions for future study.

First, like the Israeli data, our studies show that children growing up in a society with a history of conflict between social groups are especially likely to essentialise the categories which are the basis of that conflict. This was evident both within and between cultures. Within cultures, children in Northern Ireland were more essentialist about religion categories than control categories (Studies 1-3 \& 5), whereas children in Israel were more essentialist about ethnicity categories than other categories (e.g. Birnbaum et al., 2010, Diensendruck \& HaLevi, 2006). Between cultures, children in Northern Ireland reasoned differently about religion categories than children in the US (Study 4), and children in Israel reason differently about ethnicity categories than children in the US (Diesendruck, Goldfein-Elbaz et al., 2013). Thus, in both Israel and Northern Ireland, we see differential essentialist thinking about culturally salient social categories. 
Despite differences between the integrated sectors in Israel and Northern Ireland (Bekerman, Zembylas \& McGlynn, 2009), a second important similarity between Northern Ireland and Israel concerns the different developmental trajectories of essentialist reasoning among children in segregated versus integrated educational contexts. Children attending integrated schools in Northern Ireland show evidence of attenuated essentialist reasoning (Studies 1 and 2) and beliefs (Study 5) about religion categories relative to children attending segregated schools. Likewise, children attending integrated schools in Israel show evidence of attenuated essentialist beliefs about ethnicity categories relative to children attending segregated schools (Deeb et al., 2011). Thus, both case studies contain important findings relating to the effects of historical-cultural context and associations with educational diversity on how and whether essentialist reasoning about socially relevant categories is manifested.

Similarities notwithstanding, our data suggest that in important respects, development of essentialist thinking about social categories differs in Northern Ireland and Israel. First, none of the Northern Irish children included in our studies appeared to develop essentialist beliefs about religion categories until eight years of age, whereas studies consistently show that some Israeli children as young as five years of age show evidence of essentialist reasoning about ethnicity (Birnbaum et al., 2010; Diesendruck, Goldfein-Elbaz et al., 2013; Diesendruck \& HaLevi, 2006; Segall et al., 2015). Importantly, the pattern that emerged in Northern Irish children's categorybased reasoning (Studies 1-3) was confirmed in a study using a very different, and perhaps more direct, measure of essentialist beliefs (Study 5), suggesting that this difference is unlikely to be a methodological artifact. There are several reasons why essentialist reasoning about ethnicity categories in Israel may emerge earlier than essentialist reasoning about religion categories in 
Northern Ireland. First, visual and linguistic cues to ethnic category membership in Israel may make membership of such categories much more salient or outwardly obvious than cues to membership in religion categories in Northern Ireland; some theorists hold visual cues to be extremely important to social category essentialism (e.g. Gil-White, 2001). It is conceivable that because visual cues to religion category membership in Northern Ireland are less readily observable, children become aware of the importance of religion categories later in Northern Ireland than is the case for ethnicity categories in Israel. If so, attendance at a segregated school may be an important component of children's developing awareness of religion categories in Northern Ireland.

Another explanation for later emergence of social essentialist thinking in Northern Ireland involves differences in the timing of relevant input. Specifically, since the signing of the Good Friday Peace Accords in 1998 (and hence for the entire lifetime of the children in these studies), Northern Ireland has been a “post-conflict” society (e.g. Tam, Hewstone, Kenworthy \& Cairns, 2009). As such, parents in Northern Ireland might be less likely to speak of religion categories in ways that might promote essentialist thinking—such as using generic reference (e.g., Gelman, Ware \& Kleinberg, 2010). If so, perhaps essentialist reasoning about religion categories in Northern Ireland does not develop until children are taught the societal importance of such categories from some other source, such as attendance at a segregated school. In contrast, the conflict between Arabs and Jews in Israel is, as yet, unresolved, a situation which may result in more parental talk_-including generic language_-about relevant social categories. If so, the earlier input in Israel may lead to an earlier emergence of essentialist thinking about culturally relevant social categories (see Segall et al., 2015). Although clearly beyond the scope of this 
paper, identifying the causes of the differences in developmental trajectory of essentialist thinking about critical social categories in Northern Ireland and Israel is an important area for further investigation.

Although, as mentioned above, differences between children in segregated and integrated schools are evident in both Northern Ireland and Israel, a second important difference between the Northern Irish and the Israeli results is the precise nature of the school differences in the two contexts. To put it simply, in Northern Ireland, attending segregated schools is associated with an increase in essentialist thinking, whereas in Israel, attending integrated schools is associated with a decrease in essentialist thinking. One account that might explain both patterns is that the different effects represent interactions between school context and societal defaults with respect to integration of members of salient social categories. ${ }^{2}$ As we have pointed out previously, Catholics and Protestants in Northern Ireland tend to live in the same communities, and segregation tends to be on the micro level of neighborhoods rather than the macro level of towns or sectors (Lloyd \& Shuttleworth, 2011). As such, segregated schools—albeit the norm—reflect a departure from the demographic default of a relatively integrated society. Accordingly, we observe the most marked effects on essentialist thinking among children attending segregated schools in Northern Ireland. In contrast, in Israel, Jews and Arabs typically live in different communities and even different parts of the country, and therefore segregation tends to be on the macro level (for a recent study of the segregation of Arabs in Israel, see Schnell, Abu Baker Diab \& Benenson, 2015). As such, integrated schools reflect a departure from the demographic default of a relatively divided society. Accordingly, the most marked effects on essentialist thinking

\footnotetext{
${ }^{2}$ We thank an anonymous reviewer for suggesting this point.
} 
reported by Diesendruck and colleagues is among children in integrated schools. This is a potentially important hypothesis which deserves further empirical attention. Importantly, only by presenting a detailed case study of the development of essentialist thinking about social categories in a new and different historical, political, and cultural context—Northern Ireland—to be compared and contrasted with what we already know about development in Israel, was this hypothesis even brought to light.

\section{Differences Between Integrated and Segregated Schools in Northern Ireland}

Why does essentialist reasoning about religion categories emerge much more strongly among children attending segregated schools in Northern Ireland? One possibility, or course, is that spending the majority of one's time with members of one's own salient social category helps to reify that category and causes a marked increase in essentialist thinking. Of course, we cannot draw causal conclusions from the present results. Moreover, there are at least two other reasons why attendance at segregated school might be associated with essentialist beliefs about religion categories. First, as the results of our meta-analysis suggests, segregated schools may be located in segregated communities, meaning that community segregation rather than educational diversity may be the causally important factor. However, we observed almost no statistical relationship between a measure of diversity in the communities where participating schools were located, and levels of essentialist thinking about religion categories in those schools. This finding strongly suggests that the different levels of essentialist thinking associated with educational environment observed in our studies are not due to community segregation.

An alternative account of the associations with educational environment is that they are driven by parental input. As parents choose the primary school attended by their child, the school 
chosen may be an indicator of the political attitudes to which the child is exposed at home, which may be the critical component in the development of essentialist thinking (see Degner \& Dalege, 2013). Indeed, it has recently been argued that essentialism in Israel is caused more by parental language than by choice of school environment, which turns out to be predicted by parental attitudes (see Segall et al., 2015). This implies that a segregated school environment per se may play little role in the development of essentialist beliefs about ethnicity categories amongst Israeli children.

Morgan, Dunn, Cairns and Fraser (1993) found that five major factors contributed to parents in Northern Ireland choosing to send their children to integrated schools. One of these was indeed political ideology, but others included educational quality, dissatisfaction with their current school, convenience, and mixed marriage. This suggests that deciding whether to send a child to an integrated school in Northern Ireland can be a complex and multifaceted decision, and is unlikely to be based solely on political or intergroup attitudes. Clearly, further work will be required to tease apart the relative importance of parental input and school environment in the development of essentialist beliefs about religion categories in Northern Ireland.

\section{Future Directions}

Our findings highlight a number of important avenues for future investigation. As discussed above, identifying the mechanisms responsible for the different developmental trajectories among children in segregated versus integrated schools is one important area for further study. Another important avenue for future research hinted at above will be examining the role played by parental linguistic input in the development of Northern Irish children's beliefs about religion categories. Adult use of generic language (e.g, "Hamster owners are 
habitually tardy.”) appears to be an important determinant of essentialist thinking in young children (e.g., Rhodes, Leslie \& Tworek, 2012; Segall et al., 2015). As such it will be important to investigate the frequency with which parents in Northern Ireland use generic language to refer to social categories, and the age at which such use is observed.

Another important direction for future research will be to explore the underlying structure of social essentialism across a range of categories and cultural contexts. As described above, Haslam et al. (2000) have demonstrated that adults’ essentialist beliefs embody the components of naturalness and cohesiveness. However, most studies of the development of essentialist thinking utilize a single measure of such thinking. Future studies using multiple measures of essentialist reasoning such as the category naturalness task (Diesendruck, Goldfein-Elbaz et al., 2013; Rhodes and Gelman, 2009), the switched at birth task (e.g. Gelman \& Wellman, 1991; Taylor, Rhodes and Gelman, 2009) and the category stability task (Kinzler \& Dautel, 2012) may reveal a more complex and nuanced view of the development of essentialist thinking about social categories, because different tasks may tap into different dimensions of essentialist beliefs. For example, a switched at birth task may tap into beliefs about naturalness whereas the inference task may tap into the cohesiveness dimension of essentialism. Indeed, as argued above, our results support just such a view of gender categories, which children may perceive as relatively high in naturalness but relative low in cohesiveness.

A final important avenue for research will be to map out the continuing trajectory of essentialist beliefs about social categories into adolescence and adulthood in Northern Ireland. Unlike work suggesting a decrease in essentialist thinking in later childhood (e.g., Deeb et al., 2011; Taylor et al., 2009; but see Eidson \& Coley, 2014), our results show little evidence of 
decreasing essentialist thinking. Other work appears to demonstrate an important role for context in determining whether the tendency to hold essentialist beliefs about particular social categories increases or decreases in adolescence (Rhodes \& Gelman, 2009). As such, it becomes critical to characterize the entire developmental spectrum — including adults — in order to understand the role of context and experience in the development of essentialist thinking about social categories in general and conflict-relevant culturally salient social categories in particular (see Coley, 2000).

\section{Conclusions}

We have shown that children in Northern Ireland come to see religion categories like Catholic and Protestant as potent guides for inductive inferences in a way that children in the US do not. This tendency emerges by age 8 , and is especially evident among children in relatively homogeneous educational settings. When compared with the development of essentialist thinking about ethnicity categories (Arab, Jew) in Israel, these results highlight potentially universal aspects of essentialist thinking about social kinds. They reinforce the unique cognitive status of culturally salient social categories—especially those related to historical and cultural conflict—as well as the potential role of inter-group contact in attenuating essentialist thinking. They also highlight differences in the two cases, and raise questions about the differential developmental trajectories of essentialist thinking among children growing up in different historical, cultural, and political contexts, as well as in the precise mechanism by which context might influence conceptualization of social kinds. Although answering these questions will be a matter for future research, without a detailed look at the development of essentialist thinking about social kinds in a different cultural and historical context, the questions themselves might have remained undiscovered. 


\section{References}

Allport, G.W. (1954). The nature of prejudice. London: Addison-Wesley.

Bastian, B. \& Haslam, N. (2006). Psychological essentialism and stereotype endorsement. Journal of Experimental Social Psychology, 42, 228-235. doi:10.1016/j.jesp.2005.03.003

Bekerman, Z., Zembylas, M. \& McGlynn, C. (2009). Working towards the de-essentialization of identity categories in conflicted societies: Israel, Cyprus and Northern Ireland. Comparative Education Review, 53, 213-234. doi:10.1086/597482

Birnbaum, D., Deeb, I., Segall, G., Ben-Eliyahu, A. \& Diesendruck, G. (2010). The development of social essentialism: The case of Israeli children’s inferences about Jews and Arabs. Child Development, 81, 757-777. doi:10.1111/j.1467-8624.2010.01432.x

Borenstein, M., Hedges, L. V., Higgins, J. P. T., \& Rothstein, H. R. (2009). Introduction to metaanalysis. Chichester, England: Wiley \& Sons.

Byers-Heinlein, K. \& Garcia, P. (2014). Bilingualism changes children’s beliefs about what is innate. Developmental Science, 18, 344-350. doi:10.1111/desc.12248

Cimpian, A., \& Salomon, E. (2014). The inherence heuristic: An intuitive means of making sense of the world, and a potential precursor to psychological essentialism. Behavioral and Brain Sciences, 37, 461-480. doi:10.1017/s0140525x13002197

Coley, J.D. (2000). On the importance of comparative research: The case of folkbiology. Child Development, 71, 82-90. doi:10.1111/1467-8624.00121

Connolly, P. (2011). Using survey data to explore preschool children’s ethnic awareness and attitudes. Journal of Early Childhood Research, 9, 175-187. doi:10.1177/1476718x10387898 
Connolly, P., Kelly, B. \& Smith, A. (2009). Ethnic habitus and young children: A case study of Northern Ireland. European Early Childhood Education Research Journal, 17, 217-232. doi:10.1080/13502930902951460

Connolly, P., Smith, A. \& Kelly, B. (2002). Too young to notice? The cultural and political awareness of 3-6 year olds in Northern Ireland. Belfast, Northern Ireland: Community Relations Council.

Crisp, R. J. \& Turner, R, N. (2011). Cognitive adaptation to the experience of social and cultural diversity. Psychological Bulletin, 137, 242-266. doi:10.1037/a0021840

Deeb, I., Segall, G., Birnbaum, D., Ben-Eliyahu, A. \& Diesendruck, G. (2011). Seeing isn’t believing: The effect of intergroup exposure on children's beliefs about ethnic categories. Journal of Personality and Social Psychology, 101, 1139-1156. doi:10.1037/a0026107

Degner, J. \& Dalege, J. (2013). The apple does not fall far from the tree, or does it? A metaanalysis of parent-child similarity in intergroup attitudes. Psychological Bulletin, 139, 1270-1304. doi:10.1037/a0031436

Department for Education, Northern Ireland (2015). Annual enrolments at grant-aided schools in Northern Ireland 2015/16: Basic provisional statistics. Retrieved 18 February 2016 from https://www.deni.gov.uk/sites/default/files/publications/de/statistical-bulletin-annualenrolments-at-grant-aided-schools-in-Northern-Ireland-2015-16-basic-provisionalstatistics.pdf.

Diesendruck, G. (2013). Essentialism: The development of a simple, but potentially dangerous, idea. In M. Banaji \& S. Gelman (Eds.), Navigating the social world: The early years (pp 263-268). New York: Oxford University Press. 
Diesendruck, G., Birnbaum, D., Deeb, I., \& Segall, G. (2013). Learning what is essential: Relative and absolute changes in children's beliefs about the heritability of ethnicity. Journal of Cognition and Development, 14, 546-560. doi:10.1080/15248372.2012.691142

Diesendruck, G., Goldfein-Elbaz, R., Rhodes, M., Gelman, S., \& Neumark, N. (2013). Crosscultural differences in children's beliefs about the objectivity of social categories. Child Development, 84, 1906-1917. doi:10.1111/cdev.12108

Diesendruck, G., \& Haber, L. (2009). God's categories: The effect of religiosity on children's teleological and essentialist beliefs about categories. Cognition, 110, 100-114. doi:10.1016/j.cognition.2008.11.001

Diesendruck, G. \& HaLevi, H. (2006). The role of language, appearance, and culture in children’s social category-based induction. Child Development, 77, 539-553. doi: 10.1111/j.1467-8624.2006.00889.x

Eidson, R. C., \& Coley, J. D. (2014). Not so fast: Reassessing gender essentialism in young adults. Journal of Cognition and Development, 15, 382-392. doi:10.1080/15248372.2013.763810

Feeney, A., Coley, J.D. \& Crisp, A.K. (2010). The relevance framework for category-based induction: Evidence from garden path arguments. Journal of Experimental Psychology: Learning, Memory and Cognition, 36, 906-919. doi: 10.1037/a0019762

Gallagher, T. (2010). Building a shared future from a divided past. Promoting peace through education in Northern Ireland. In G. Salomon \& E. Cairns (Eds.) Handbook on Peace Education (pp. 241-251). New York: Psychology Press. 
Gelman, S. A. (2003). The essential child: Origins of essentialism in everyday thought. New York: Oxford University Press.

Gelman, S. A., Collman, P., \& Maccoby, E. E. (1986). Inferring properties from categories versus inferring categories from properties: The case of gender. Child Development, 57, 396-404. doi:10.2307/1130595

Gelman, S.A., Ware, E.A. \& Kleinberg, F. (2010). Effects of generic language on category content and structure. Cognitive Psychology, 61, 273-301.

doi:10.1016/j.cogpsych.2010.06.001

Gelman, S.A. \& Wellman, H.W. (1991). Insides and essences: Early understandings of the nonobvious. Cognition, 38, 213-244. doi:10.1016/0010-0277(91)90007-q

Gil-White, F. J. (2001). Are ethnic groups biological species to the human brain? Essentialism in our cognition of some social categories. Current Anthropology, 42, 515-554. doi:10.1086/321802

Gillespie, G. (2010). A short history of the Troubles. Dublin: Gill \& Macmillan.

Haslam, N., Bastian, B., Bain, P. \& Kashima, Y. (2006). Psychological essentialism, implicit theories, and intergroup relations. Group Processes \& Intergroup Relations, 9, 63-76. doi:10.1177/1368430206059861

Haslam, N. O., Rothschild, L., \& Ernst, D. (2000). Essentialist beliefs about social categories. British Journal of Social Psychology, 39, 113-127. doi:10.1348/014466600164363

Hewstone, M., Cairns, E., Voci, A., Paolini, S., McLernon, F., Crisp, R., Niens, U. \& Craig, J. (2005). Intergroup contact in a divided society: Challenging segregation in Northern 
Ireland. In D. Abrams, J. M. Marques \& M. A. Hogg (Eds.), The social psychology of inclusion and exclusion (pp. 265-292). Philadelphia: Psychology Press.

Hirschfeld, L. A. (1996). Race in the making: Cognition, culture, and the child's construction of human kinds. Cambridge, Massachusetts: MIT Press.

Kinzler, K. D. \& Dautel, J. B. (2012). Children’s essentialist reasoning about language and race. Developmental Science, 15, 131-138. doi:10.1111/j.1467-7687.2011.01101.x

Kuperman, V., Stadthagen-Gonzalez, H. \& Brysbaert, M. (2012). Age-of-acquisition ratings for 30,000 English words. Behavior Research Methods, 44, 978-990. doi:10.3758/s13428-0120210-4

Leslie, S. J., Cimpian, A., Meyer, M., \& Freeland, E. (2015). Expectations of brilliance underlie gender distributions across academic disciplines. Science, 347, 262-265. doi:10.1126/science.1261375

Lloyd, K. \& Robinson, G. (20011). Intimate mixing - bridging the gap? Catholic-Protestant relationships in Northern Ireland. Ethnic and Racial Studies, 34, 2134-2152. doi.org/10.1080/01419870.2011.574716

Lloyd, C.D. \& Shuttleworth, I.G. (2012). Residential segregation in Northern Ireland in 2001: Assessing the value of exploring spatial variations. Environment and Planning A, 44, 5267. doi:10.1068/a44167

Mahalingham, R. (2003). Essentialism, culture and power: Representations of social class. Journal of Social Issues, 59, 733-749. doi:10.1046/j.0022-4537.2003.00087.x 
Medin, D. L. \& Ortony, A. (1989). Psychological essentialism. In S. Vosniadou \& A. Ortony (Eds.), Similarity and analogical reasoning (pp. 179-195). New York: Cambridge University Press.

Morgan, V., Dunn, S., Cairns, E. \& Fraser, G. (1993). How do parents choose a school for their child? An example of the exercise of parental choice. Educational Research, 35, 139-148. doi:10.1080/0013188930350203

Nisbett, R. E., Krantz, D. H., Jepson, D., \& Kunda, Z. (1983). The use of statistical heuristics in everyday reasoning. Psychological Review, 90, 339-363. doi.org/10.1037/0033295X.90.4.339

Northern Ireland Council for Integrated Education. (2007). Annual report. Retrieved September 3, 2013, from http://www.nicie.org/publications/reports/page/3/

Northern Ireland Neighbourhood Information Service (2012). Census 2011 - Religion: KS211NI (administrative geographies). Retrieved 30 May, 2016 from http://www.ninis2.nisra.gov.uk/public/PivotGrid.aspx?ds=7478\&lh=38\&yn=2011\&sk=136 \&sn=Census $\% 202011 \&$ yearfilter $=$.

Northern Ireland Statistics and Research Agency (2014). Northern Ireland Census 2011 key statistics summary report. Retrieved 18 February, 2016 from http://www.nisra.gov.uk/archive/census/2011/results/key-statistics/summary-report.pdf.

Pauker, K., Ambady, N. \& Apfelbaum, E. P. (2010). Race and essentialist thinking in racial stereotype development. Child Development, 81, 1799-1813. doi:10.1111/j.14678624.2010.01511.x 
Pettigrew, T. F. (1998). Intergroup contact theory. Annual Review of Psychology, 49, 65-85. doi:10.1146/annurev.psych.49.1.65

Pew Research Centre (2014). America’s changing religious landscape. Retrieved February 18, 2016, from http://www.pewforum.org/files/2015/05/RLS-08-26-full-report.pdf.

Prentice, D. A. and Miller, D. T. (2007). Psychological essentialism of human categories. Current Directions in Psychological Science, 16, 202-206. doi:10.1111/j.14678721.2007.00504.x

Rangel, U. \& Keller, J. (2011). Essentialism goes social: Belief in social determinism as a component of social essentialism. Journal of Personality and Social Psychology, 100, 1056-1078. doi:10.1037/a0022401

Rhodes, M. (2013). How two intuitive theories shape the development of social categorization. Child Development Perspectives, 7, 12-16. doi:10.1111/cdep.12007

Rhodes, M. \& Gelman, S. A. (2009). A developmental examination of the conceptual structure of animal, artifact, and human social categories across two cultural contexts. Cognitive Psychology, 59, 244-274. doi:10.1016/j.cogpsych.2009.05.001

Rhodes, M., Leslie, S. J., \& Tworek, C. M. (2012). Cultural transmission of social essentialism. Proceedings of the National Academy of Sciences, 109, 13526-13531. doi:10.1073/pnas.1208951109

Rothbart, M. \& Taylor, M. (1992). Category labels and social reality: Do we view social categories as natural kinds? In G.R. Semin \& K. Fiedler (Eds.) Language, interaction and social cognition (pp. 11-36). Thousand Oaks, CA: Sage Publications, Inc. 
Schnell, I., Abu Baker Diab, A. \& Benenson, I. (2015). A global index for measuring sociospatial segregation versus integration. Applied Geography, 58, 179-188.

doi:10.1016/j.apgeog.2015.01.008

Segall, G., Birnbaum, D., Deeb, I., \& Diesendruck, G. (2015). The intergenerational transmission of ethnic essentialism: How parents talk counts the most. Developmental Science, 18, 543555. doi:10.1111/desc.12235

Sherif, M., Harvey, O.J., White, B.J., Hood, W.R. \& Sherif, C.W. (1961). Intergroup conflict and cooperation: The Robbers Cave experiment. Norman, OK: University Book Exchange.

Shuttleworth, I.G. \& Lloyd, D.L. (2009). Are Northern Ireland’s communities dividing? Evidence from geographically consistent Census of Population data, 1971-2001. Environment and Planning A, 41, 213-229. doi:10.1068/a40163

Tajfel, H. (1982). Social psychology of intergroup relations. Annual Review of Psychology, 33, 1-39. doi:10.1146/annurev.ps.33.020182.000245

Tam, T., Hewstone, M., Kenworthy, J. \& Cairns, E. (2009). Intergroup trust in Northern Ireland. Personality and Social Psychology Bulletin, 35, 45-59. doi:10.1177/0146167208325004

Taylor, M.G. \& Gelman, S.A. (1993). Children’s gender- and age-based categorization in similarity and induction tasks. Social Development, 2, 104-121. doi:10.1111/j.14679507.1993.tb00006.x

Taylor, M. G., Rhodes, M., \& Gelman, S. A. (2009). Boys will be boys; Cows will be cows: Children's essentialist reasoning about gender categories and animal species. Child Development, 80, 461-481. doi:10.1111/j.1467-8624.2009.01272.x 
Taylor, M. G. (1996). The development of children’s beliefs about social and biological aspects of gender differences. Child Development, 67, 1555-1571. doi:10.1111/j.14678624.1996.tb01814.x

Yzerbyt, V. Y., Corneille, O., \& Estrada, C. (2001). The interplay of subjective essentialism and entitativity in the formation of stereotypes. Personality and Social Psychology Review, 5, 141-155. doi:10.1207/s15327957pspr0502_5 
Table 1. Demographic information on participants in Study 1

\begin{tabular}{|c|c|c|}
\hline School Type & Age Group & Religion \\
\hline \multirow[t]{4}{*}{ State Controlled } & $6-7$ years old: $N=19$ & Catholic: 0\% \\
\hline & $8-9$ years old: $\mathrm{N}=20$ & Protestant: $66 \%$ \\
\hline & $10-11$ years old: $N=20$ & Other/Mixed: 5\% \\
\hline & & Not Religious: $29 \%$ \\
\hline \multirow[t]{4}{*}{ Catholic Maintained } & $6-7$ years old: $\mathrm{N}=19$ & Catholic: 89\% \\
\hline & $8-9$ years old: $\mathrm{N}=20$ & Protestant: $0 \%$ \\
\hline & $10-11$ years old: $N=17$ & Other/Mixed: 9\% \\
\hline & & Not Religious: 2\% \\
\hline \multirow[t]{4}{*}{ Integrated } & $6-7$ years old: $N=19$ & Catholic: $29 \%$ \\
\hline & $8-9$ years old: $N=20$ & Protestant: $19 \%$ \\
\hline & $10-11$ years old: $N=20$ & Other/Mixed: 15\% \\
\hline & & Not Religious: $37 \%$ \\
\hline
\end{tabular}


Table 2: Demographic information on participants in Study 2.

\begin{tabular}{lll}
\hline School Type & Age Group & Religion \\
\hline State Controlled & $6-7$ years old: $\mathrm{N}=18$ & Catholic: $0 \%$ \\
& $8-9$ years old: $\mathrm{N}=20$ & Protestant: $87.5 \%$ \\
& $10-11$ years old: $\mathrm{N}=18$ & Other/Mixed: $9 \%$ \\
& & Not Religious: $3.5 \%$ \\
\hline Catholic Maintained & $6-7$ years old: $\mathrm{N}=17$ & Catholic: $94 \%$ \\
& $8-9$ years old: $\mathrm{N}=21$ & Protestant: $2 \%$ \\
\hline $10-11$ years old: $\mathrm{N}=16$ & Other/Mixed: $2 \%$ \\
\hline Integrated & Not Religious: $2 \%$ \\
\hline $10-11$ years old: $\mathrm{N}=18$ & Catholic: $53 \%$ \\
& & Protestant: $9 \%$ \\
\hline
\end{tabular}


Table 3. Demographic information on participants in Study 3

\begin{tabular}{|c|c|c|}
\hline School Type & Age Group & Religion \\
\hline \multirow[t]{4}{*}{ State Controlled } & $6-7$ years old: $N=20$ & Catholic: 0\% \\
\hline & $8-9$ years old: $N=26$ & Protestant: 93\% \\
\hline & $10-12$ years old: $\mathrm{N}=28$ & Other/Mixed: 3\% \\
\hline & & Not Religious: $4 \%$ \\
\hline \multirow[t]{4}{*}{ Catholic Maintained } & $6-7$ years old: $N=27$ & Catholic: $86 \%$ \\
\hline & $8-9$ years old: $N=28$ & Protestant: $11.5 \%$ \\
\hline & $10-12$ years old: $\mathrm{N}=23$ & Other/Mixed: 0\% \\
\hline & & Not Religious: $2.5 \%$ \\
\hline \multirow[t]{4}{*}{ Integrated } & $6-7$ years old: $N=26$ & Catholic: $42 \%$ \\
\hline & $8-9$ years old: $N=24$ & Protestant: $30 \%$ \\
\hline & $10-12$ years old: $N=26$ & Other/Mixed: 5\% \\
\hline & & Not Religious: $22 \%$ \\
\hline
\end{tabular}


Table 4: Mean inferences based on religion, gender, and control categories for US children.

Note that chance $=2 / 4,+\mathrm{p}<.10,{ }^{*} \mathrm{p}<.05, * * \mathrm{p}<.01, * * * \mathrm{p} \leq .001$.

\begin{tabular}{llccc}
\hline \multicolumn{1}{c}{ Age Group } & \multicolumn{3}{c}{ Social Dimension } & Mean \\
\cline { 2 - 4 } & Religion & Pet Ownership (Control) & Gender & $2.58(0.88)^{* * *}$ \\
\hline 6-yr-olds & $2.83(1.09)^{* * *}$ & $2.80(1.06)^{* * *}$ & $2.10(1.03)$ & $2.39(1.00)$ \\
8-yr-olds & $2.56(1.20)+$ & $2.56(1.15)+$ & $2.06(1.16)$ & $2.07(0.92)$ \\
10-yr-olds & $2.37(1.38)$ & $2.00(1.11)$ & $1.84(1.07)$ & \\
\hline Mean & $2.63(1.20)^{* * *}$ & $2.51(1.13)^{* * *}$ & $2.01(1.07)$ & \\
\hline
\end{tabular}


Table 5: Demographic information on participants in Study 5.

\begin{tabular}{lll}
\hline School Type & Age Group & Religion \\
\hline Catholic Maintained & 6-7 years old: $\mathrm{N}=16$ & Catholic: $91.5 \%$ \\
& 8-9 years old: $\mathrm{N}=15$ & Protestant: $0 \%$ \\
& $10-11$ years old: $\mathrm{N}=16$ & Other/Mixed: $6.5 \%$ \\
& & Not Religious: $2 \%$ \\
\hline Integrated & 6-7 years old: $\mathrm{N}=16$ & Catholic: $44.5 \%$ \\
& & Protestant: $34 \%$ \\
& & Other/Mixed: $8.5 \%$ \\
\hline
\end{tabular}


Table 6: Factor loading of each dimension from the Essentialism Components Questionnaire.

\begin{tabular}{lcccccc}
\hline \multirow{2}{*}{ Question } & \multicolumn{2}{c}{ Religion } & \multicolumn{3}{c}{ Gender } & \multicolumn{2}{c}{ Pet Ownership } \\
& Distinctive & Stable & Distinctive & Stable & Distinctive & Stable \\
\hline 1. What they like & .70 & -.33 & .72 & .03 & .70 & .09 \\
2. How they behave & .53 & -.42 & .49 & .12 & .68 & -.01 \\
$\begin{array}{l}\text { 3. How they look } \\
\text { 4. What they have inside their }\end{array}$ & .65 & -.01 & .77 & -.21 & .64 & -.11 \\
$\begin{array}{l}\text { body } \\
\text { 5. What they think }\end{array}$ & .66 & -.009 & .44 & .008 & .74 & .11 \\
$\begin{array}{l}\text { 6. Possibility of category } \\
\text { change }\end{array}$ & .74 & .09 & .72 & -.03 & .62 & -.14 \\
$\begin{array}{l}\text { 7. Possibility of joint } \\
\text { membership }\end{array}$ & .16 & .77 & -.002 & .88 & -.15 & .82 \\
\end{tabular}


Table 7. Meta analytic effects of category (religion vs. control) in each of the schools, and community diversity in each of the associated wards, included in Studies 1, 2, 3, and 5, grouped by School Type.

\begin{tabular}{|c|c|c|c|c|c|c|}
\hline $\begin{array}{l}\text { School } \\
\text { Type }\end{array}$ & $\begin{array}{l}\text { Study } \\
\text { (Ward) }\end{array}$ & $\begin{array}{l}\text { Std difference in } \\
\text { means }\end{array}$ & $\begin{array}{l}\text { Standard } \\
\text { error }\end{array}$ & $\begin{array}{l}\text { 95\% Confidence } \\
\text { Limit } \\
\end{array}$ & $\begin{array}{l}Z- \\
\text { Value }\end{array}$ & $p$ \\
\hline \multirow[t]{6}{*}{ Integrated } & 1 (a) & -0.20 & 0.21 & {$[-0.61,0.22]$} & -0.94 & 0.349 \\
\hline & 1 (b) & 0.34 & 0.17 & {$[0.00,0.67]$} & 1.96 & 0.050 \\
\hline & 2 (c) & -0.05 & 0.13 & {$[-0.31,0.22]$} & -0.36 & 0.721 \\
\hline & $3(d)$ & 0.57 & 0.16 & {$[0.26,0.87]$} & 3.64 & $>0.001$ \\
\hline & $3(e)$ & 0.07 & 0.19 & {$[-0.31,0.44]$} & 0.35 & 0.729 \\
\hline & $5(f)$ & 0.11 & 0.15 & {$[-0.17,0.40]$} & 0.77 & 0.44 \\
\hline \multicolumn{2}{|c|}{$\begin{array}{l}\text { Category Effect, } \\
\text { Integrated Sector }\end{array}$} & 0.15 & 0.11 & {$[-0.07,0.37]$} & 1.34 & 0.18 \\
\hline \multirow[t]{14}{*}{ Segregated } & 1 (g) & 0.87 & 0.44 & {$[-0.00,1.74]$} & 1.96 & 0.051 \\
\hline & $1(h)$ & 0.24 & 0.16 & {$[-0.08,0.55]$} & 1.45 & 0.15 \\
\hline & 1 (i) & 0.30 & 0.14 & {$[0.02,0.58]$} & 2.12 & 0.034 \\
\hline & $1(\mathrm{j})$ & 0.72 & 0.27 & {$[0.18,1.25]$} & 2.64 & 0.008 \\
\hline & $2(k)$ & 0.84 & 0.34 & {$[0.18,1.50]$} & 2.50 & 0.012 \\
\hline & $2(\mathrm{I})$ & 0.06 & 0.15 & {$[-0.24,0.35]$} & 0.38 & 0.704 \\
\hline & $2(\mathrm{~m})$ & 0.29 & 0.18 & {$[-0.05,0.63]$} & 1.65 & 0.098 \\
\hline & $2(n)$ & 0.29 & 0.23 & {$[-0.15,0.74]$} & 1.29 & 0.198 \\
\hline & $3(0)$ & 0.19 & 0.16 & {$[-0.13,0.50]$} & 1.15 & 0.252 \\
\hline & $3(p)$ & 0.40 & 0.15 & {$[0.10,0.71]$} & 2.59 & 0.009 \\
\hline & $3(q)$ & 0.51 & 0.20 & {$[0.12,0.89]$} & 2.57 & 0.010 \\
\hline & $3(r)$ & 0.27 & 0.16 & {$[-0.05,0.59]$} & 1.66 & 0.098 \\
\hline & $5(s)$ & -0.04 & 0.26 & {$[-0.47,0.55]$} & 0.15 & 0.88 \\
\hline & $5(t)$ & 0.30 & 0.18 & {$[-.05, .66]$} & 1.67 & 0.09 \\
\hline \multicolumn{2}{|c|}{$\begin{array}{l}\text { Category Effect, } \\
\text { Segregated Sector }\end{array}$} & 0.30 & 0.05 & {$[0.20,0.40]$} & 6.00 & $>0.001$ \\
\hline \multicolumn{2}{|c|}{ Category Effect Overall } & 0.27 & 0.05 & {$[0.19,0.36]$} & 6.02 & $>0.001$ \\
\hline
\end{tabular}


Table 8. Results of meta-regression predicting essentialist reasoning about religion categories from community diversity.

\begin{tabular}{llllll}
\hline Covariate & $\begin{array}{l}\text { Regression } \\
\text { Coefficient }\end{array}$ & $\begin{array}{l}\text { Standard } \\
\text { Error }\end{array}$ & $\begin{array}{l}\text { 95\% Confidence } \\
\text { Interval }\end{array}$ & Z-value & $\mathbf{p}$ \\
\hline Intercept & 0.19 & 0.10 & {$[-0.001,0.380]$} & 1.95 & 0.051 \\
Community Diversity & 0.002 & 0.002 & {$[-0.002,0.006]$} & 0.82 & 0.500 \\
\hline
\end{tabular}




\section{Figures}

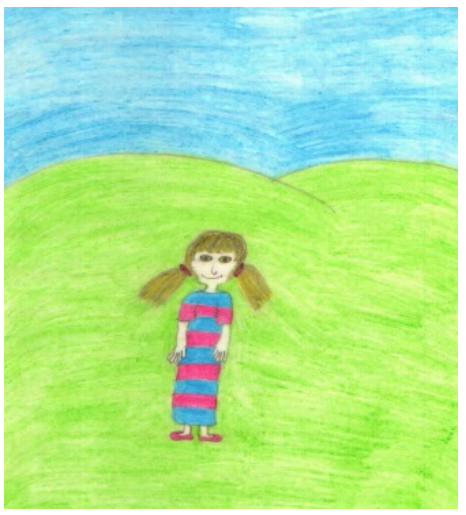

Target picture. 'This child here goes to a Catholic Church like this child (points to test picture 1), and owns a goldfish like this child (points to test picture 2). Do you think this child is 'flirst' like this child here (points to test picture 1) or 'legan' like this child here (points to test picture 2)?

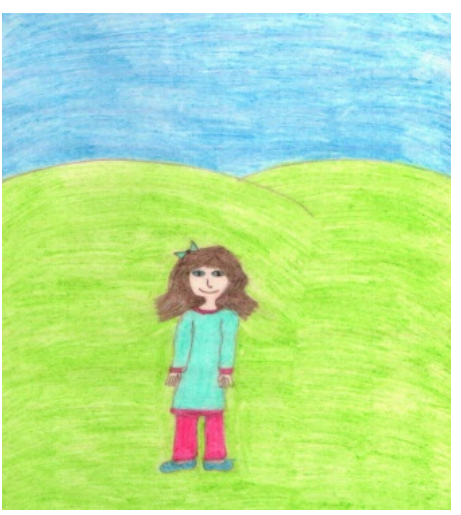

Base picture 1. 'This child here goes to a Catholic Church and owns a hamster. This child here is flirst.'

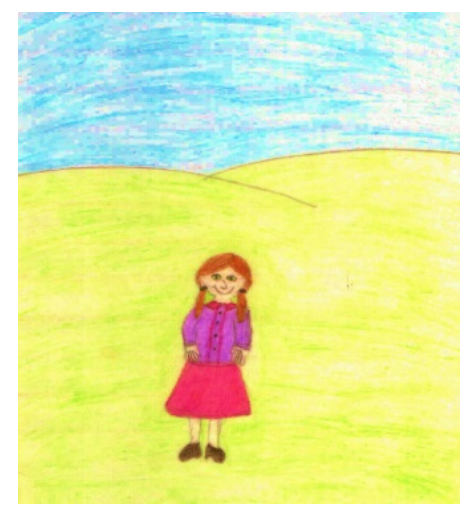

Base picture 2. 'This child here goes to a Protestant Church and owns a goldfish. This child here is legan'.

Figure 1: A sample triad from Experiment 1 which forced children to choose between control and religion category membership as a basis for social inference. 
(A) Religion v Control Trials

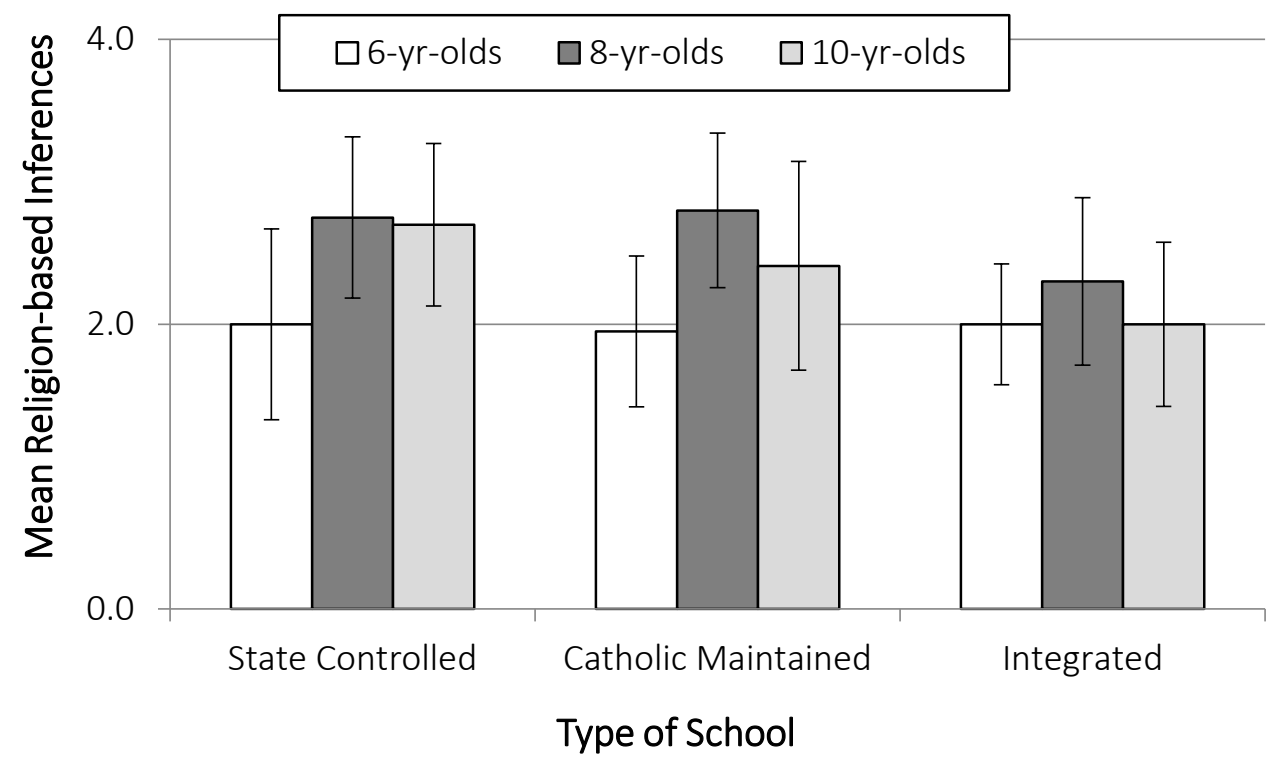

(B) Religion v Gender Trials

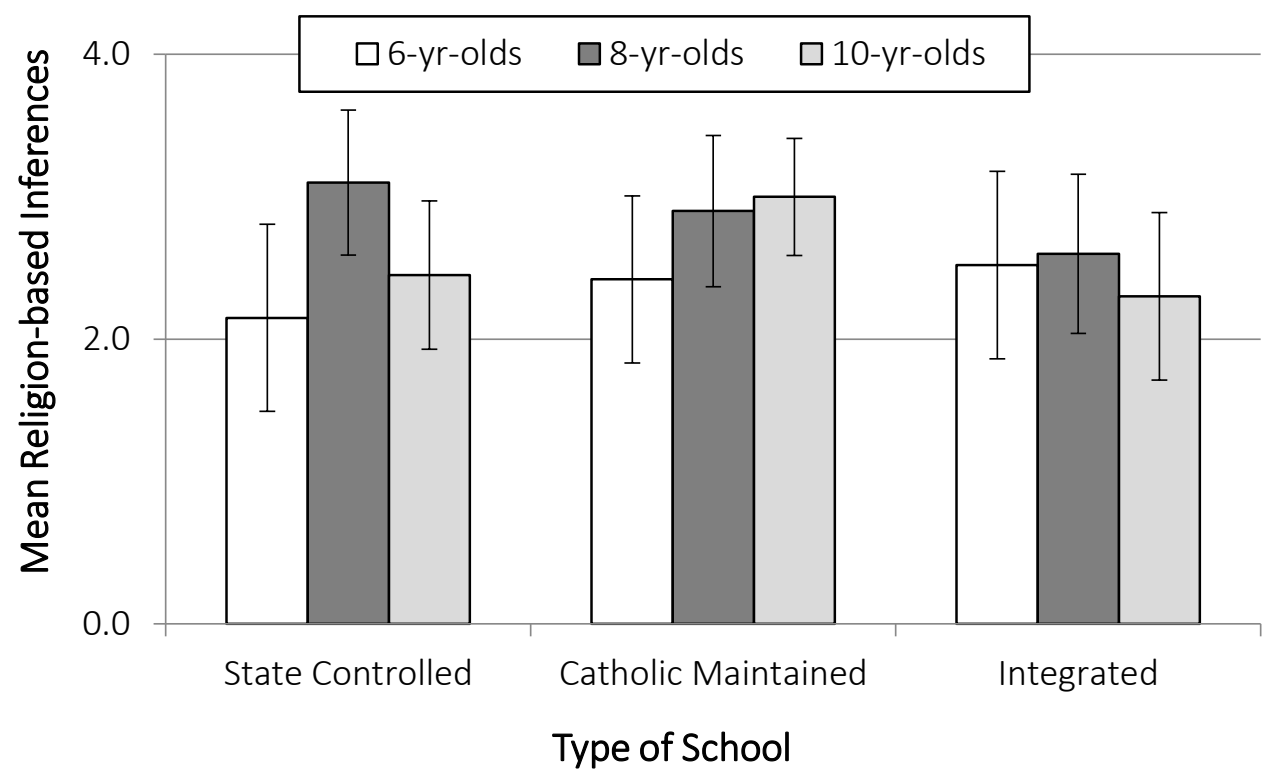


(C) Gender v Control Trials

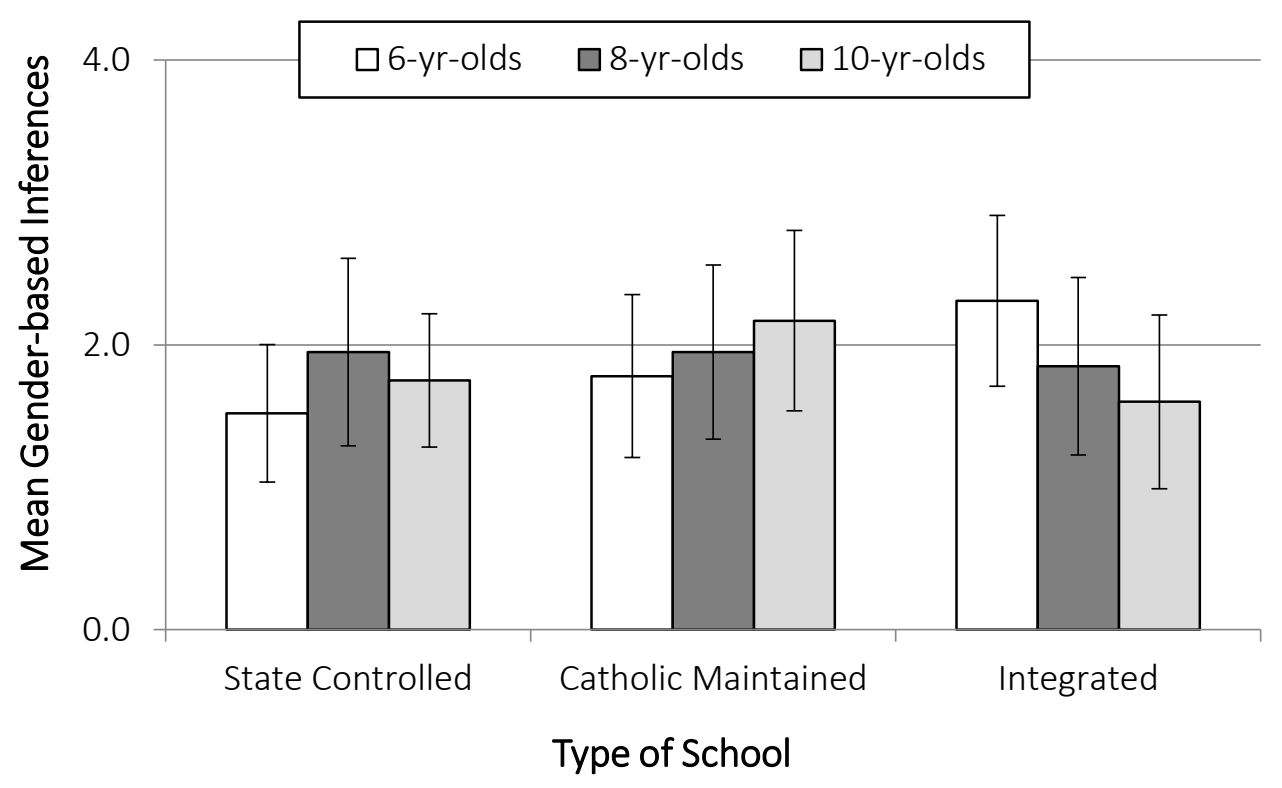

Figure 2: Inferences (out of 4), broken down by School Type and Age, for each pairing of dimensions in Study 2. (A) Religion-based inferences for religion v control trials. (B) Religionbase inferences for religion v gender trials. (C) Gender-based inferences for gender v control trials. Error bars represent 95\% confidence intervals. 


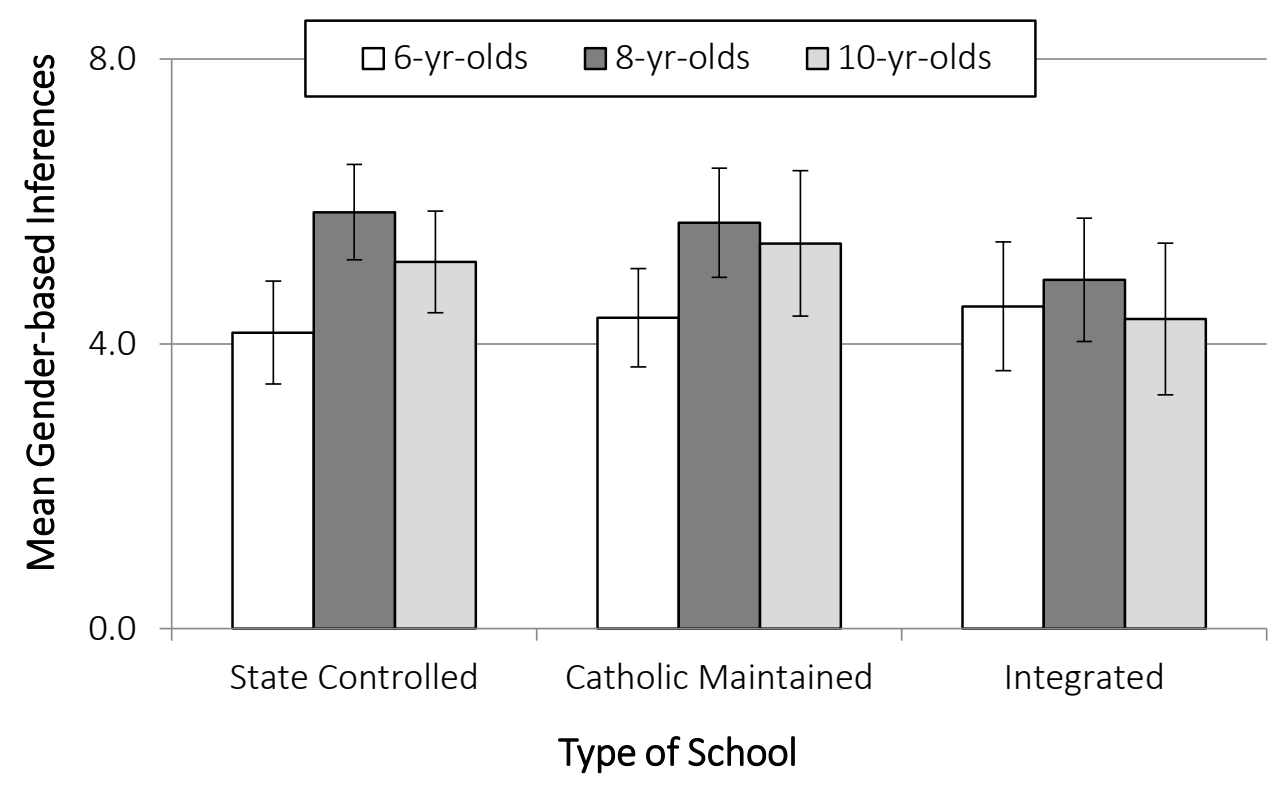

Figure 3: Mean number of religion-based inferences (out of a maximum of eight) made by children in Study 1, broken down by age group, and school type. Error bars represent 95\% confidence intervals. 


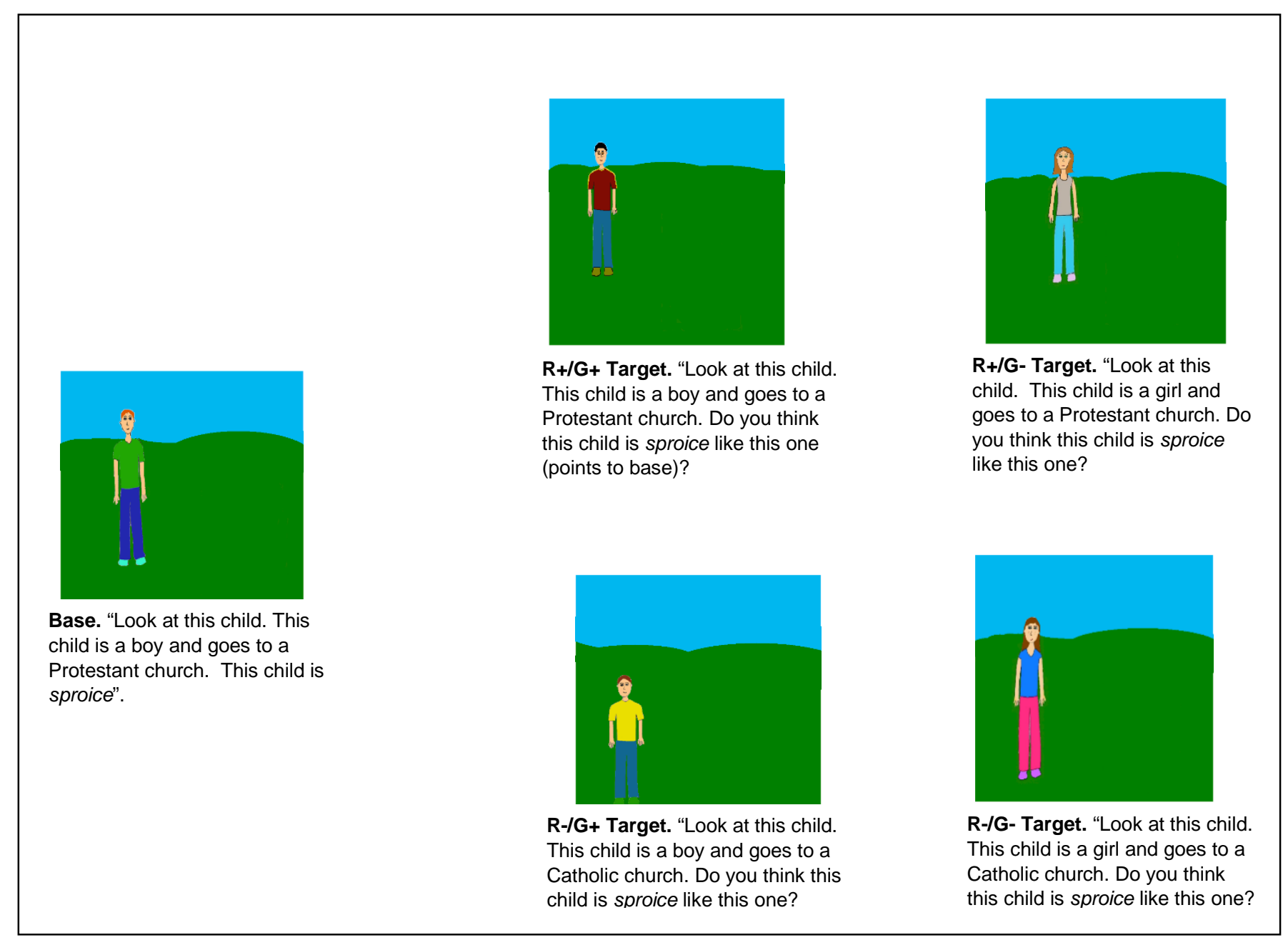

Figure 4: Sample set of base and target pictures for religion/gender trials in Study 2. Note that each target picture is labeled by its relationship to the base. For example, $\mathrm{R}+\mathrm{G}+$ shares religion and gender category membership with the base whereas the R-G- target child shares membership of neither category. 


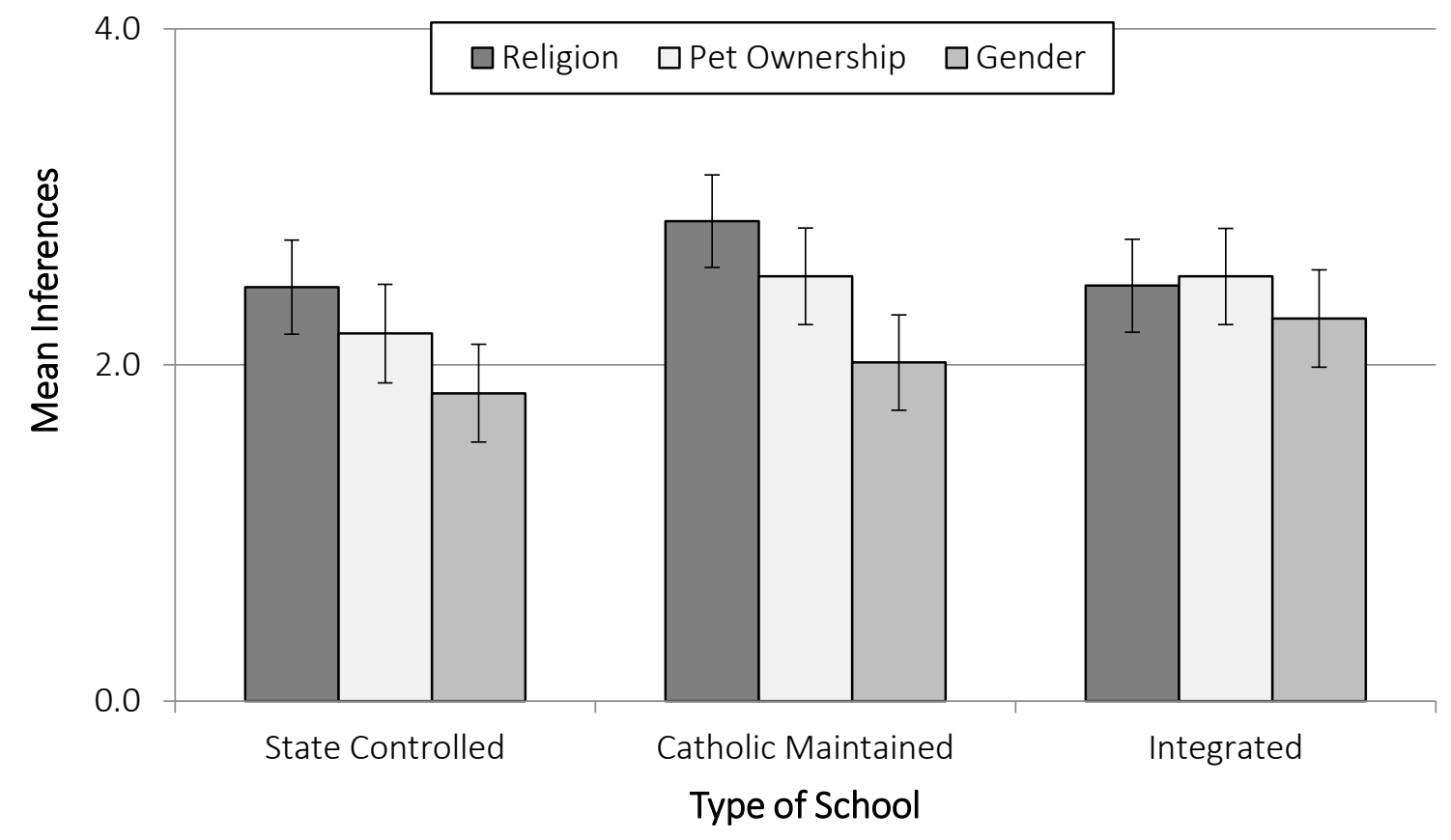

Figure 5: Mean number of inferences (out of a maximum of four) based on religion, pet ownership, and gender, for children in state controlled, catholic maintained, and integrated school in Study 2. Error bars represent 95\% confidence intervals. 


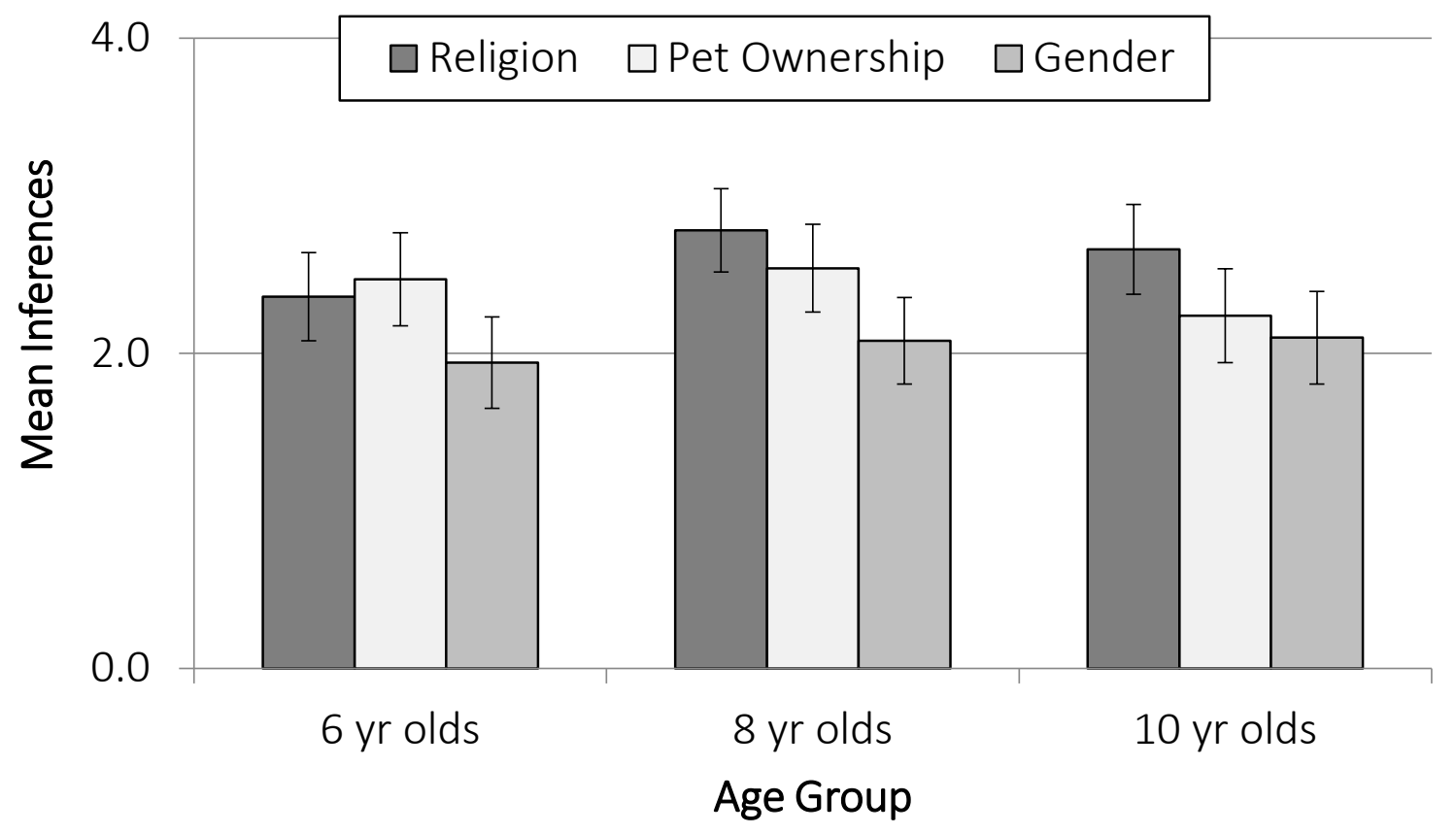

Figure 6: Mean number of inferences (out of a maximum of four) based on religion, pet ownership, and gender, for 6, 8, and 10-year-old age groups in Study 2. Error bars represent 95\% confidence intervals. 


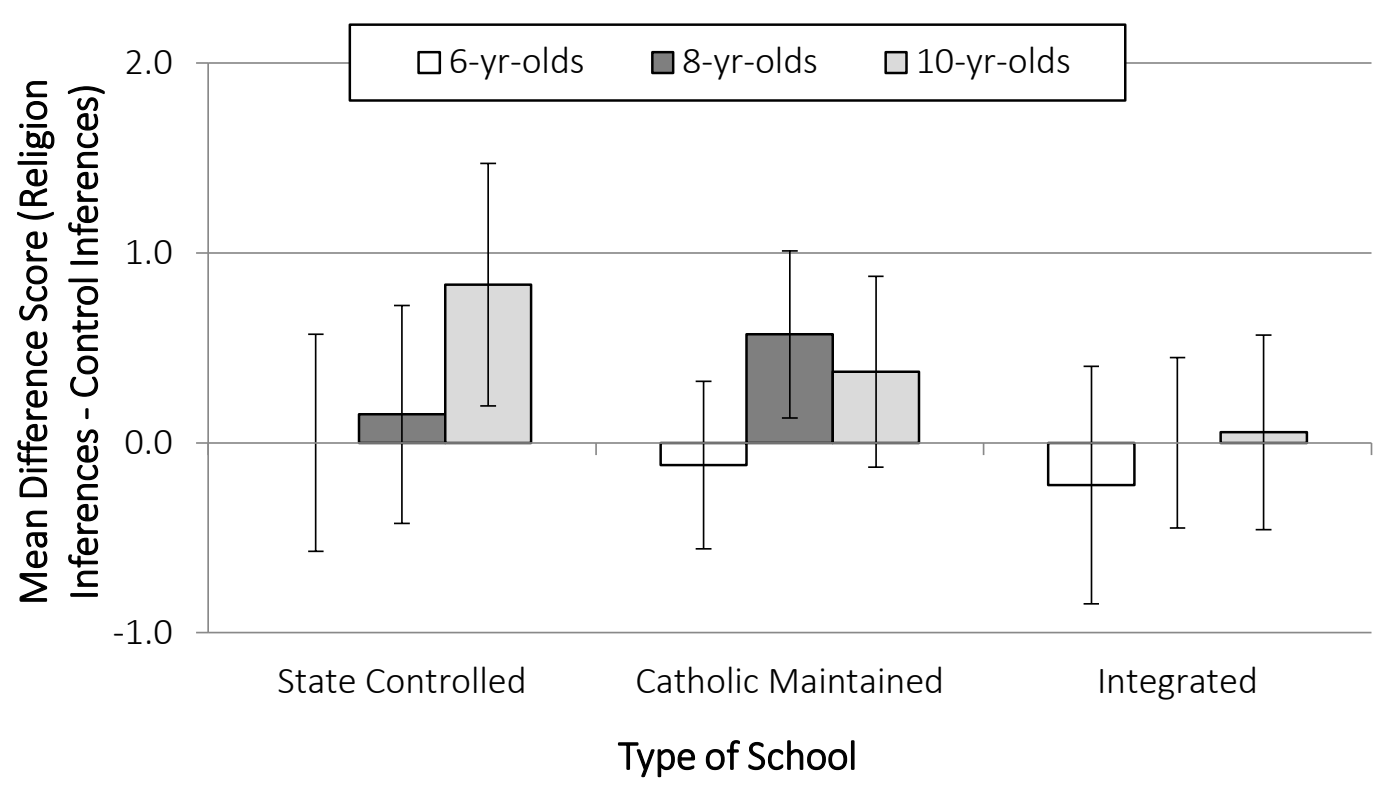

Figure 7: Mean difference score (number of religion-based inferences minus number of pet-based inferences) in Study 2 broken down by age group and school type. Error bars represent 95\% confidence intervals. 


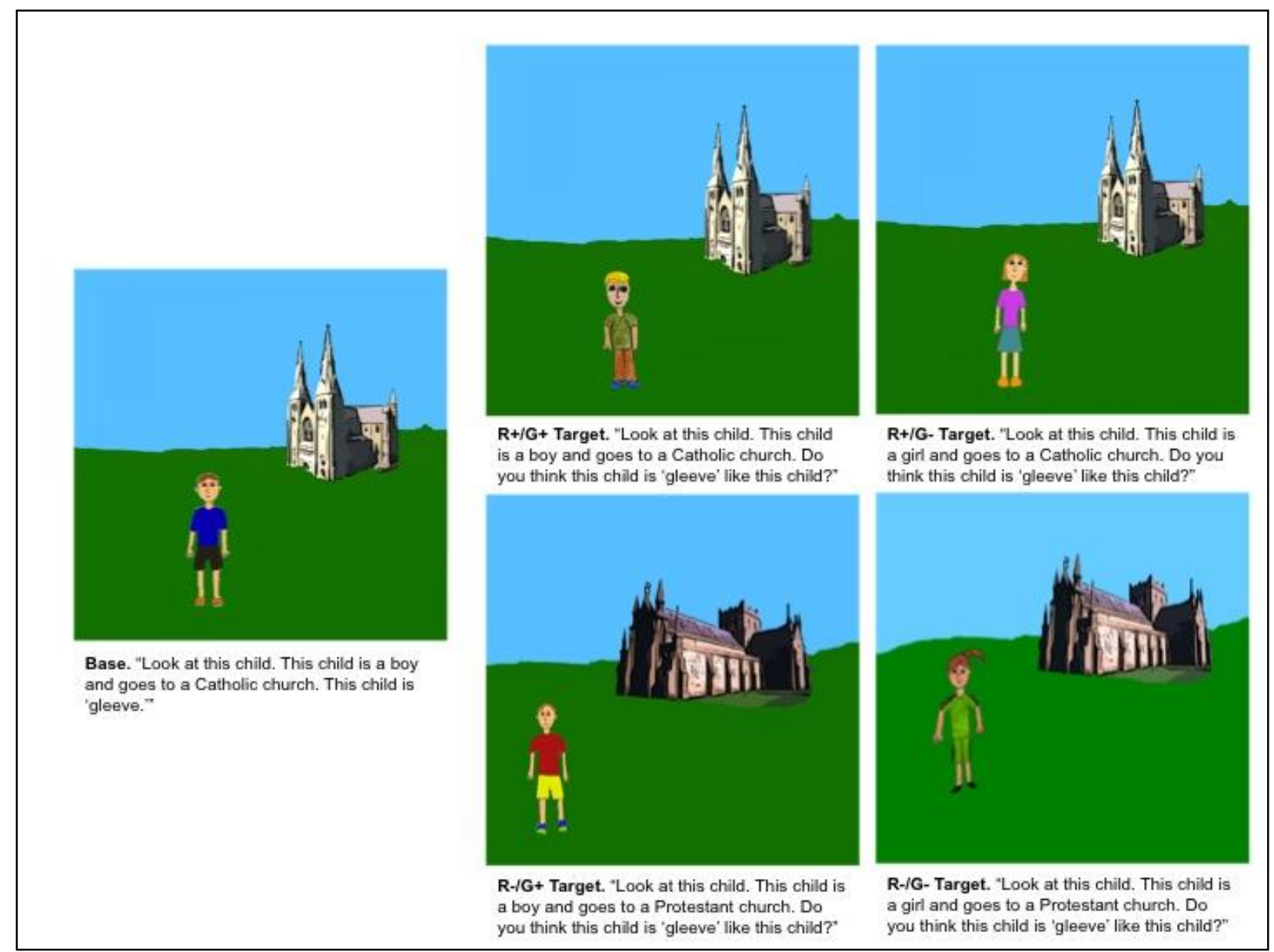

Figure 8: Sample set of base and target pictures for religion/gender trials in Study 3. Note that

each target picture is labeled by its relationship to the base. For example, $\mathrm{R}+\mathrm{G}+$ shares religion and gender category membership with the base whereas the R-G- target child shares membership of neither category. 


\section{$\square$ Religion $\square$ Pet Ownership $\quad \square$ Gender}

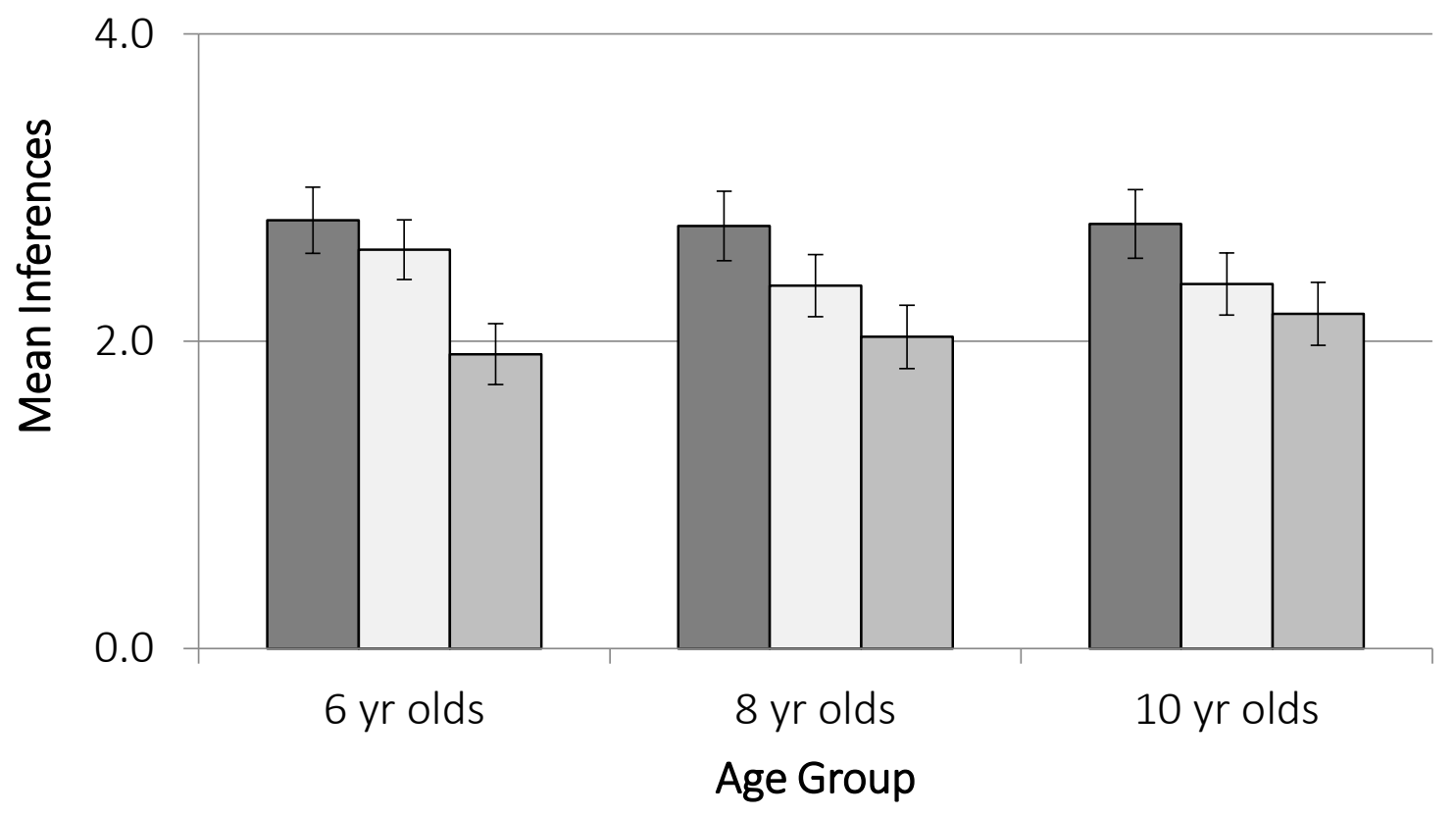

Figure 9: Mean number of inferences (out of a maximum of four) based on religion, pet ownership, and gender, for 6, 8, and 10-year-old age groups in Study 3. Error bars represent 95\% confidence intervals. 


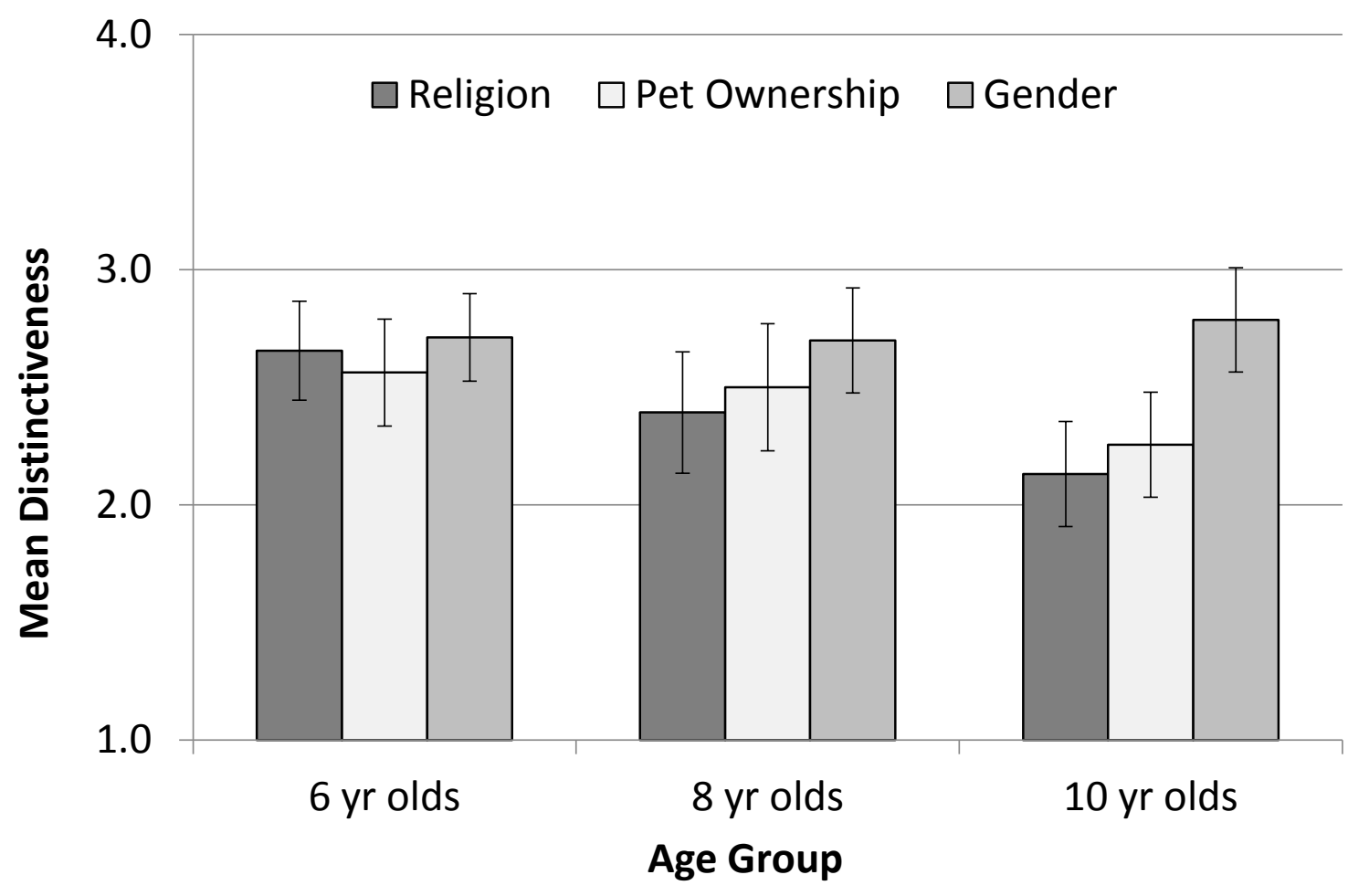

Figure 10: Mean distinctiveness score for religion, pet ownership, and gender categories for 6, 8, and 10-year-old age groups in Study 5. Error bars represent 95\% confidence intervals. 
(A) Stability: Age x Dimension

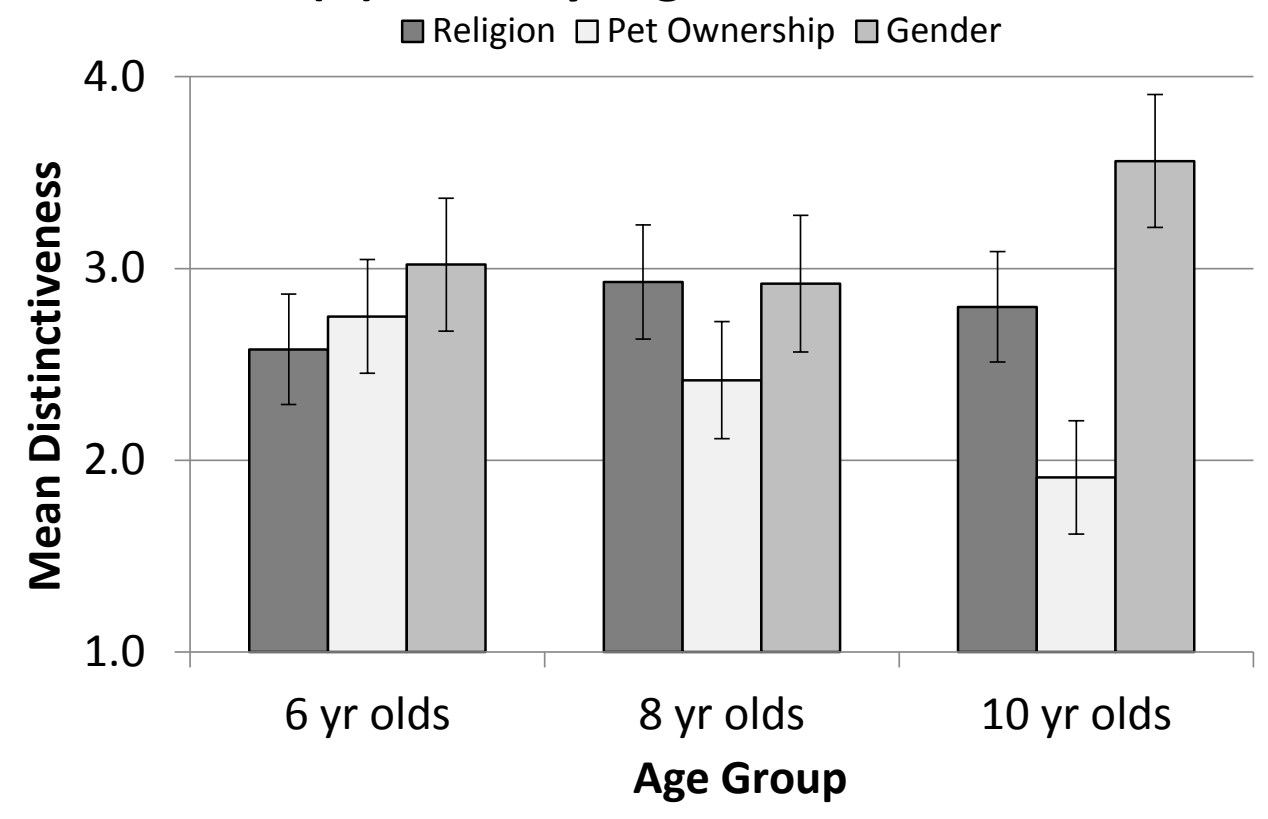

(B) Stability: School x Dimension, 10-year-olds only

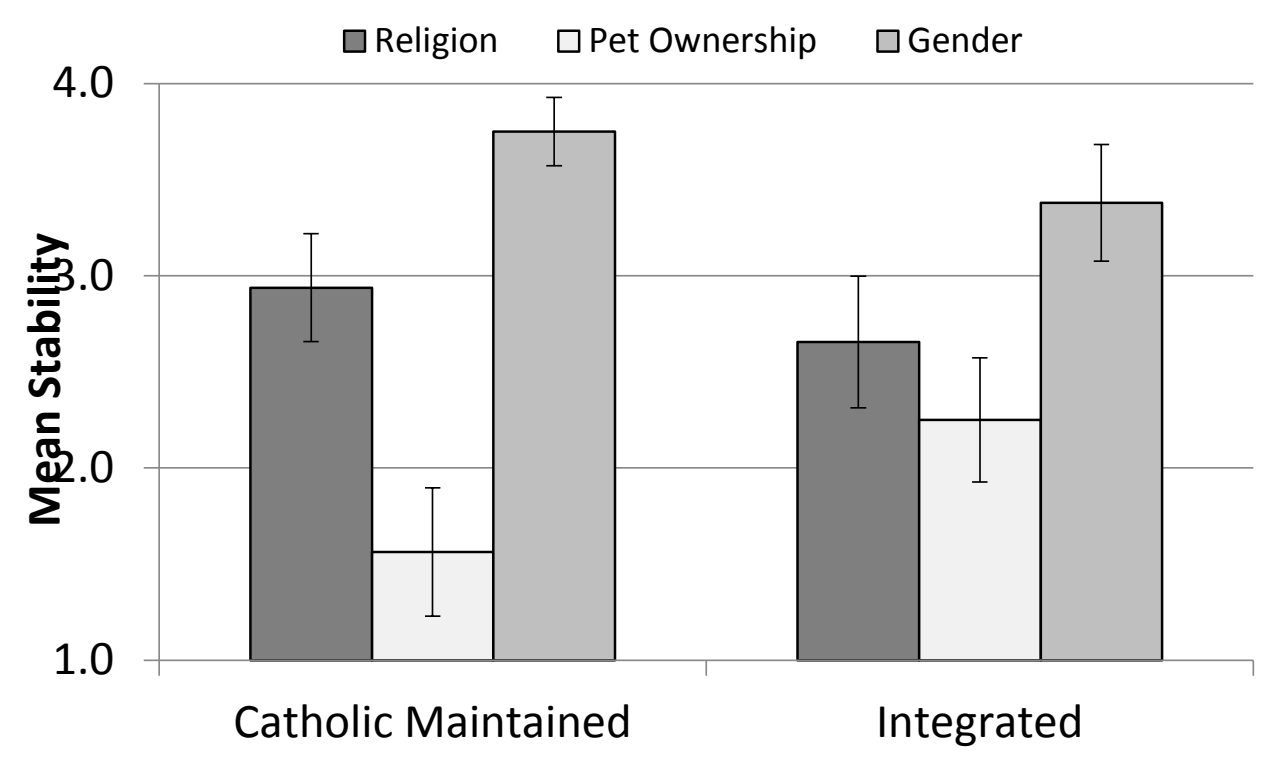

Figure 11: (A) Mean stability score for religion, pet pet ownership, and gender categories for 6, 8, and 10-year-old age groups in Study 5. (B) Mean stability scores by social dimension for 10year-olds attending Catholic Maintained and Integrated Schools. Error bars represent 95\% confidence intervals. 


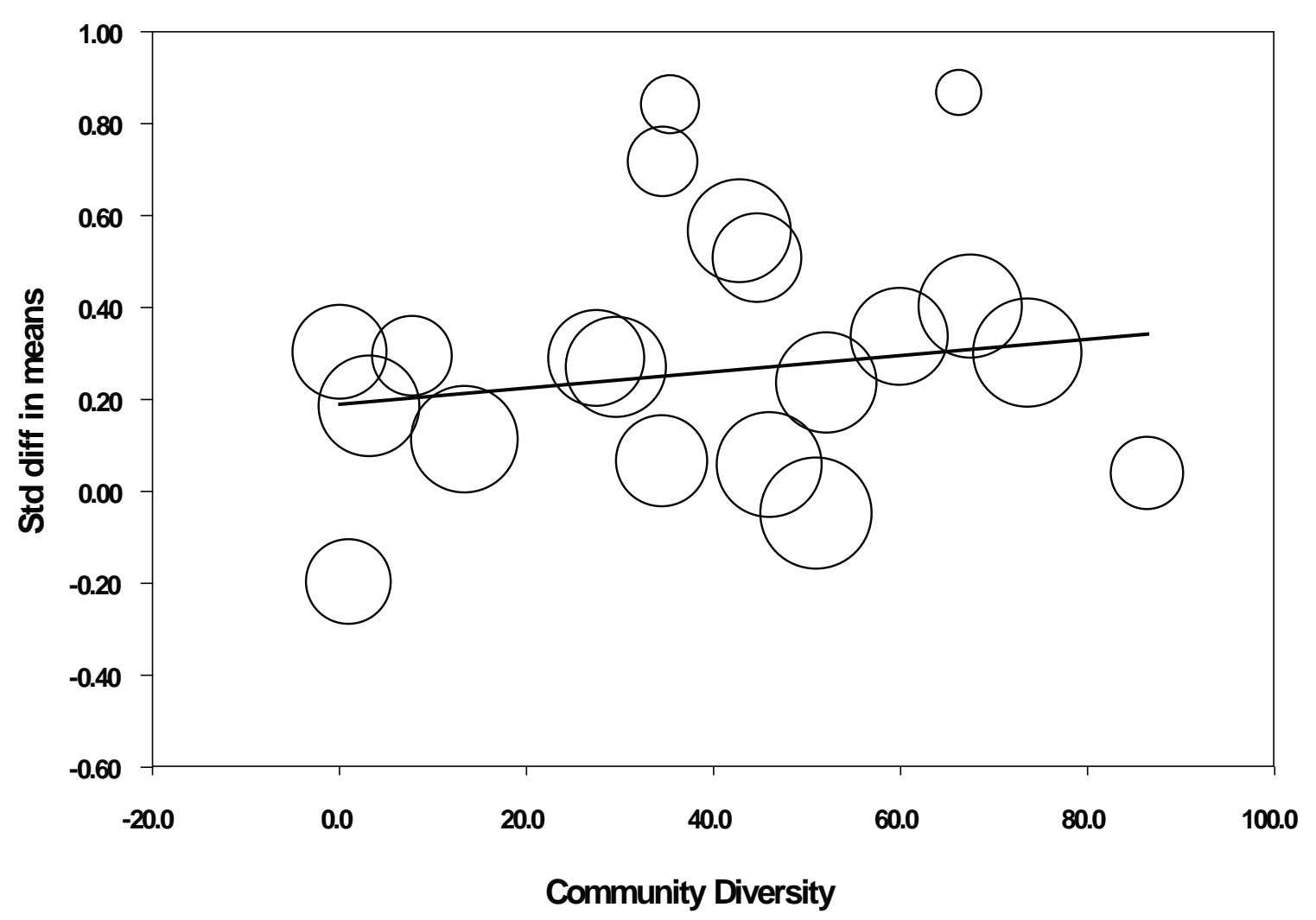

Figure 12: Scatterplot showing relationship between the diversity of the community in which each participating school was located and the standardized difference between the means for religion and control categories. 